INVITED REVIEW

\title{
Expected future developments in child neurology
}

\author{
Ingrid Tein 123 \\ ${ }^{1}$ Division of Neurology, Dept. of Pediatrics and ${ }^{2}$ Genetic and Genome Biology Program,The Research \\ Institute, The Hospital for Sick Children, and ${ }^{3}$ Dept. of Laboratory Medicine and Pathobiology, The \\ University of Toronto, Toronto, ON, Canada M5G 1X8
}

Corresponding author:Ingrid Tein, The University of Toronto, Toronto, ON, Canada M5G 1X8; Email: ingtein@sympatico.ca; Tel: +1-416-813-5668.

do) https://doi.org/10.17724/jicna.2019.158

Received: 18 Feb 2018

Accepted: 21 July 2019

Published 18 Nov 2019

\begin{abstract}
We stand on the shoulders of giants on the threshold of many new exciting developments in the field of child neurology due to innovations in clinical approach, diagnostic technologies and treatment strategies. There are many exciting new technologies, but we must never forget the power of clinical medicine which allows us to interpret and use these tools with precision and with clinical wisdom. Strong collaborations continue to be needed: between clinicians for the meticulous clinical phenotyping, expansion of the range of phenotypic expression, and the entry of patients into international RCTs (randomised controlled trials); between the biochemists for the biochemical phenotyping and understanding of the basic pathophysiology of the underlying dysregulations and disease mechanisms arising from the protein dysfunctions and the development of robust biomarkers, to evaluate disease severity and response to therapies; and between the geneticists for the understanding of the impact of the exonic or intronic mutations, roles of other regulatory genes on the affected pathway, and epigenetic factors. These collaborations in the aggregate will lead the field forward in terms of increased insight into disease pathophysiology for the development of targeted precision medicine treatment strategies and effective preventative measures. This review is meant to highlight certain selected areas of future development and is not meant to be a comprehensive survey beyond the scope of this review. The subspecialty areas which will be highlighted will include intellectual disability, epilepsy, neuroprotection, neonatal and fetal neurology, CNS infections, headache, autoimmune/inflammatory disorders, demyelinating disorders, stroke, movement disorders, neurotransmitter defects, neuromuscular diseases, neurometabolic disorders, neurogenetic diseases, neuropsychiatry/autism, and neurooncology. In each subspecialty area, I will endeavor to identify emerging diseases, new specific diagnostic technologies and novel therapeutic approaches, but will need to be selective. This review is the culmination of a literature survey for current developments, discussions with leaders in each of the subspecialty fields, who I will acknowledge at the end, and certain personal projections.
\end{abstract}

Keywords: child neurology; precision medicine; whole exome sequencing; randomised controlled trials

(C) 2019 Tein I; licensee JICNA. All rights reserved

\section{General approach: The way forward}

As we open Pandora's box in all fields of medicine, we are faced with a 'tsunami ' of genetic information arising from the powerful new genetic technologies of whole exome ( $1 \%$ of the genome) and whole genome sequencing. In the case of the identification of known pathogenic variants in the interrogation of genes targeted for a given clinical phenotype, the interpretation of the results will be relatively straightforward. Should previously unidentified variants of uncer- tain significance (VUS) be identified, the need then arises to determine whether these same variants are carried by the parents of a given child and whether they are symptomatic, particularly in the case of autosomal dominant genes. In the case of autosomal recessive disorders in which two VUS's are identified in a target gene in any given child, it becomes critical to determine whether the VUS's are in cis or in trans, to decide whether they may predispose to a given phenotype. This may be further complicated, as in the case of the common nuclear mitochondrial gene POLG (polymerase 
gamma) which may account for up to $25 \%$ of mitochondrial disorders, in that any given child may have both dominant and recessive variants, which in the aggregate lead to a mitochondrial phenotype (Chinnery and Zeviani, 2008). The analysis of whether the VUS's are pathogenic if previously not identified as pathogenic in an affected individual, would require biochemical or proteomic evaluation, either in vitro in human cells or in vivo in an animal model, to confirm pathogenicity. There are also several bioinformatics computational programs, such as SIFT (Ng and Henikoff, 2001), Polyphen-2 (Adzhubei et al., 2010) and Mutation taster (www.mutationtaster.org), which may be used to predict the pathogenicity of the variation, based upon the significance of the nucleotide change. For example, whether it changes an amino acid residue and if so, whether the change is significant (e.g. causing a change in charge, polarity, bending of the secondary structure of the protein, etc.) and does it occur in a residue that is highly conserved throughout the species? Additional challenges to interpretation may arise from conditions in which a pathogenic variant in an autosomal recessive condition may lead to a clinical phenotype when combined with a disease susceptibility polymorphism, such as in short-chain acyl-CoA dehydrogenase (SCAD) deficiency (Zolkipli et al., 2011). With whole exome sequencing (WES), the cDNAs encoding the expressed proteins is elucidated, which covers $1 \%$ of the genome. It is only with whole genome sequencing (WGS) that intronic mutations, which may for example affect the splicing of a protein, that the entire gene can be interrogated. Thus there may be eloquent exonic as well as intronic mutations in a given gene, contributing to the clinical phenotype. The resulting phenotypes may be further complicated by the presence of promoter regions of the gene and epigenetic modifiers that lower the threshold for disease expression. To further complicate the picture, disease phenotypes may also arise from multiple partial defects in one or more metabolic pathways, leading to the phenomenon of synergistic heterozygosity (Vockley et al, 2000). These patients show clinical symptoms consistent with a defect in the affected pathway even though they do not have a complete deficiency in any one given enzyme.

In the case of the identification of new genes of which the function is not clearly known, the interpretation of the results becomes even more challenging, particularly if the protein product is not known. This may then require sitedirected mutagenesis or CRISPR/Cas9 genome-editing technology, and in vivo animal models and in vitro human cell cultures, to ascertain clinical and biochemical phenotype(s) arising respectively. In most cases, the most severe phenotypes for a given gene disorder are elucidated first. Over time, as more variants and/or mild disease-causing mutations are identified, there is often an expansion of the clinical phenotype from mild to severe. Using these technologies, pathways can be interrogated to understand the pathophysiologic mechanisms of specific mutations, which will provide the basis for the development of targeted therapeutic strategies, e.g. to push through or bypass a biochemical block/dysfunction, modify 'loss of function' or 'gain of function' mutations, reduce secondary downstream effects, employ the use of small molecule chaperone therapies to refold misfolded proteins, etc.

With this explosion of new genetic information, the role of the skilled clinician in identifying and defining the range of the clinical phenotypes, as well as the role of the biochemist in ascertaining the effect of the mutation on protein structure and function, will therefore become even more important in order to interpret the significance of the results of WES and WGS. International collaborations and databases (e.g. Leiden Open Variation Database 3.0, etc.) to combine clinical, biochemical, proteomic and genetic information, and to define genotype-phenotype correlations, will become essential to move all fields of medicine forward.

New genetic technologies will routinely involve computational biology, epigenetic studies, genome-wide association studies (GWAS), DNA microarray technology and whole exome sequencing.

Computational biology includes areas of molecular cell biology with the application of mathematical theory to characterise the principles underlying biology at cellular, molecular and genetic levels to advance discovery, and includes foundations in computer science, applied mathematics, biostatistics, biochemistry, chemistry, biophysics, molecular biology and genetics.

Epigenetics is the study of changes in gene activity that do not involve alterations to the genetic code, but are inherited and are governed by the cellular material, the epigenome, that overlies the genome, e.g. DNA methylation and histone modification, both of which serve to upregulate gene expression without altering the underlying DNA sequence. The various techniques to identify epigenetic modifications to DNA may include mapping locus-specific differences in DNA modification, using enzymes that recognise the same target sequence in DNA but are either sensitive or insensitive to its modification, exposing DNA to bisulphites and then sequencing, to allow methylated sites to be identified, and using chemical approaches or antibodies, targeted to specific modifications.

Genome-wide association studies (GWAS) will enable researchers to identify genes involved in human illnesses and search the genome for small variations, called single nucleotide polymorphisms (SNPs) that occur more frequently in individuals with a particular illness than those without the illness. Once identified, this ideally allows clinicians to develop better strategies to detect, treat and prevent the disease, e.g. in complex diseases, such as neuropsychiatric diseases and cancer.

DNA microarray technology allows the measurement of the expression levels of large numbers of genes simultaneously, to detect SNPs or to genotype multiple regions of a genome. Since an array can contain tens of thousands of probes, a microarray experiment can accomplish many genetic tests simultaneously and accelerate investigations, especially in complex illnesses, such as neuropsychiatric disorders. 
Whole exome sequencing (WES) selectively sequences the coding regions of the genome, the regions in genes that are translated into proteins. In the human genome there are about 180,000 exons which represent $1 \%$ of the entire genome. It is estimated that most disease-causing mutations are found in the regions of the genome that encode proteins.

\section{Precision Medicine}

Precision medicine will be the next major paradigm shift in medicine. In the past we had symptom-based data with clinical intuition, which today has become pattern and evidence-based medicine. Our next move will be toward consensus algorithmic approaches and reference databases, and we will use personal genetic information and biochemical/biophysical profiling to design targeted therapies for specific mutations. These may be gain or loss of function and will dictate precision medicine for the treatment and prevention of specific diseases. There will be personal molecular fingerprinting and molecular imaging which will be interpreted in the context of big data analytics and reference databases. Mobile information communication technologies will be used to provide a precision medicine approach targeted at disease prevention, diagnosis and treatment.

\section{Intellectual Disability New diseases}

We will be looking at the further expansion of new categories of diseases, such as: (a) disorders of complex lipid synthesis and remodeling, of which there are now at least 100 subtypes, including pathways for phospholipid and sphingolipid synthesis; (b) disorders of subcellular transport and trafficking, such as the class III phosphoinositide 3 kinase (PI3K), which synthesises phosphoinositide 3 phosphatase (PI3P), regulating endosome-lysosome trafficking and the induction of autophagy, pathways involved in pathogen killing, antigen processing and immune cell survival (Hawkins and Stephens, 2015). Phosphoinositides (PIs) are a group of key signaling and structural lipid molecules involved in a myriad of cellular processes. PI phosphatases, together with PI kinases, are responsible for the conversion of PIs between distinctive phosphorylation states (Hsu and Mao, 2015), and (c) disorders of the cellular cytoskeleton, such as the 'tubulin code' disorders which have the potential to modulate microtubule structure, dynamics and interactions with associated proteins in neurons, and which have become increasingly important in both neurodegenerative and neurodevelopmental disorders, such as lissencephaly (Chakraborti et al., 2016). The tubulin code is believed to regulate microtubule functions on a cellular and subcellular level. Current advances in knowledge of the tubulin code on the molecular and functional level will increase understanding of the process of complex signaling events in controlling microtubule function, particularly in the central nervous system.

Novel Diagnostics Novel diagnostics in intellectual dis- ability and also other subspecialties of child neurology may include pharmacoimaging, high-resolution in vivo spectroscopy, and metabolomics for individual metabolic profiles.

(a) Pharmacoimaging is the union between imaging and pharmacology that provides additional information that could not otherwise be obtained using traditional techniques. It allows for a more precise, faster and direct translation of data from a preclinical to a clinical context. Evidence has now been accumulated, pointing to the potential role of imaging in mitigating risk and cost during drug development. This is done by validating targets, obtaining early indicators of bioactivity, assessing pharmacokinetic profiles, confirming mechanism(s) of action, providing prognostic indicators and supporting regulatory filings. Molecular imaging, using a variety of targeted probes such as quantum dots, and instrumentation such as optical magnetic resonance (MR) and positron emitting tomography (PET) methods, provides insights into target validation and disease mechanism issues that are critical in preclinical studies. It is hoped that greater use of imaging during pre-clinical stages will facilitate more effective translation from animal models to human subjects, by minimising changes in experimental paradigms while the model organism is changed. In addition, imaging can frequently provide critical supportive data for regulatory approval. Pharmacoimaging may also be useful for optimising combination treatments of novel compounds or compounds already in clinical trials.

(b) High-resolution in vivo spectroscopy in the brain using 1H-MRS (proton magnetic resonance spectroscopy) may be useful for screening for specific disorders and also for evaluating the effect of treatments by measuring specific biomarkers, e.g. elevated N-acetyl-L-aspartate (NAA) in Canavan's disease, elevated lactate peaks in mitochondrial disorders, decreased creatine peaks in the creatine deficiency disorders (creatine transporter defect, arginine:glycine amidinotransferase (AGAT) and guanidinoacetate methyltransferase (GAMT) deficiencies), increased guanidinoacetate (GAA) peaks in GAMT deficiency and decreased choline peaks in disorders of myelin. These MRS profiles may undergo further resolution and expansion in the future.

(c) Metabolomics is the systematic study of the unique chemical fingerprints that specific cellular processes leave behind, namely the study of their small-molecule metabolite profiles. The metabolome represents the collection of all metabolites in biological cells, tissues, organs or organisms, which are the end products of cellular processes. Metabolic profiling can give an instantaneous snapshot of the physiology of that cell. One of the challenges of systems biology and functional genomics is to integrate proteomic, transcriptomic, and metabolomic information to provide a better understanding of cellular biology. Metabolomics, particularly in small molecule diseases such as the use of tandem mass spectrometry (MS/MS) in fatty acid oxidation disorders allows a snapshot of the physiology of the cell in a given 
disease (e.g. used in newborn screening) and can be used to monitor the impact of therapies. The Human Metabolome Database (HMDB 4.0) for 2018, using in silico approaches, along with more traditional manual curation, has expanded to 114,000 metabolites (Wishart et al., 2018).

Novel Therapies In intellectual disability, as well as in all other subspecialties of child neurology, novel therapies may include (a) cell-based and gene-based therapies, (b) small molecule chaperone therapies for misfolded proteins, e.g. in lysosomal storage disorders, and (c) stop codon readthrough therapies for missense and nonsense mutations (Keeling et al., 2014). Nonsense suppression therapy encompasses approaches aimed at suppressing translation termination at in-frame premature termination codons (PTCs), also known as nonsense mutations, to restore deficient protein function. The approaches include readthrough drugs, suppressor tRNAs, PTC pseudouridylation, and inhibition of nonsense-mediated mRNA (messenger ribonucleic acids) decay. A further therapy, (d) antisense oligonucleotide (AON) therapy, corrects splicing defects through exon skipping (e.g. Duchenne dystrophy) (Aartsma-Rus et al., 2007; van Roon-Mom and Aartsma-Rus, 2012). AONs are short synthetic modified nucleic acids that bind RNA through base-pairing, and enable modulation of its expression (Southwell et al., 2012; Siva et al., 2014). The design of AONs that can bind to splice sites or to exonic- or intronicenhancing cis-regulatory sequences in the pre-mRNA (exonic splice enhancers (ESEs) or intronic splice enhancers (ISEs)) leads to the masking of these regions and the inability of trans-splicing regulatory factors to bind effectively, thus inducing switching between alternative splice isoforms via exon skipping. In the same way, by the masking of cryptic splice sites, AONs have been used for the correction of cryptic splicing. With their diverse functionality, high target specificity, and the relative ease of central nervous system (CNS) delivery, they are uniquely positioned as potential therapies for neurological diseases.

\section{Epilepsies}

New Diseases In the future, epileptic encephalopathies will be thought of as 'developmental' epileptic encephalopathies in order to encapsulate the developmental aspects of the child in addition to the epileptic component. The epilepsies will be classified according to the genetic mutations, e.g. STXBP1 encephalopathy, which may present with an early infantile epileptic encephalopathy, characterised by infantile spasms or myoclonic, atonic or absence seizures due to syntaxin-binding protein 1 mutations. There will also be an increased understanding of immune-mediated epilepsies, e.g. anti-GAD (glutamic acid decarboxylase) 65 antibody-mediated epilepsy. Epileptic encephalopathies of infancy and childhood comprise a large, heterogeneous group of severe epilepsies characterised by several seizure types, frequent epileptiform activity on EEG, and often developmental slowing or regression (McTague et al.,
2015). The epileptic encephalopathies include many age-related electroclinical syndromes with specific seizure types and EEG features. There may be evolution from one age-related epilepsy syndrome to another, e.g. Ohtahara syndrome (early infantile epileptic encephalopathy) beginning in the first two months of life, evolving into infantile spasms and later into Lennox-Gastaut syndrome (Ohtahara, 1977). The number of known monogenic determinants underlying the epileptic encephalopathies is growing rapidly with the identification of molecular mutations. De-novo dominant mutations are frequently identified, along with somatic mosaicism and recessive disorders. Mosaicism in both the somatic and germline cells is becoming increasingly important in order to understand pathophysiology, particularly in patients in whom exome and gene panel sequencing is negative. Whole genome sequencing may be needed to identify intronic mutations and regulatory components of the genome. Furthermore, epigenetic regulation (including methylome) may also need investigation and may help to explain phenotypic pleiotropy. One gene might be associated with phenotypic pleiotropy and conversely, several genes can cause one electroclinical syndrome. As more genes are identified, specific genetic epileptic encephalopathies are being identified with distinctive electroclinical features and comorbidities, allowing classification of disorders in patients which was not previously possible (Thomas et al., 2015; Howell et al., 2015).

Diverse genetic causes and molecular pathways have been implicated, which may involve ion channels and proteins needed for synaptic, regulatory and developmental functions. Gene discovery provides the basis for neurobiological insights, often showing convergence of mechanistic pathways (McTague et al., 2015). These findings will underpin the development of targeted therapies, essential to improve the outcome of these severe neurological disorders. In the future, models of network dysfunction in a given individual will require the development of sophisticated in silico models in addition to in vitro models from patient-derived stem cells, in order to understand the pathomechanisms of dysfunction (McTague et al., 2015). In the case of early onset epileptic encephalopathies (e.g. serine deficiency due to 3-phospoglycerate dehydrogenase deficiency) (de Koning et al., 2004), effective therapy may require prenatal administration to reduce the effects of these devastating disorders.

Further expansion of knowledge In the future, there will be a further expansion of the knowledge related to the neurobiology of severe epilepsies. The disease mechanisms may include synaptic dysfunction, channelopathies, transporter defects, dysregulation of transcription, impaired repair of DNA and the remodeling of chromatin as well as metabolic disorders (McTague et al., 2015). Bioinformatic approaches with computer modeling and in vitro and in vivo models of epilepsy will be used to identify links between different disease mechanisms, which may show convergence of disease pathways (Noebels 2015; Oliver et al., 2014). Pat- 
terns of spatial expression, including certain cell types, brain regions or networks may also be important in epileptic encephalopathies, e.g. abnormalities of interneuron development, migration or function, are associated with the ARX and SCN1A genes (Yu et al., 2006; Kitamura et al., 2002). In addition, the temporal expression of genes may predict the timing of the onset of the epilepsy, e.g. KCNQ2 and GRIN2A-related epilepsies will typically present around the age when gene expression is needed for the normal physiological development of neurons (Carvill et al., 2013; Lesca et al., 2013; Weckhuysen et al., 2012). Furthermore, genetic causes of severe epilepsy may also affect neuronal function through mechanisms different from the seizure disorder, such as abnormal neuronal migration or abnormal network formation, which may lead to abnormal cognitive development (Bender et al., 2013). Novel Therapeutics (a) Pharmacologic approaches that directly target the abnormal protein or disrupted pathways: (i) Mutations in the sodiumgated potassium channel gene KCNT1 may present with epilepsy of infancy with migrating focal seizures (EIMFS) with five times the gain of function over the wild type, which begins in early infancy ( $<$ six months of age), or with autosomal dominant nocturnal frontal lobe epilepsy (ADNFLE) with three times the gain of function, which begins much later in mid-childhood. The phenotypes can be reversed with quinidine which crosses the blood-brain barrier and reversibly blocks the channel in humans and rodents (Milligan et al., 2014). (ii) Retigabine opens Kv7 potassium channels consisting of KCNQ2 and KCNQ3 subunits and restores normal channel function of KCNQ2 encephalopathy mutations in vitro (Orhan et al., 2014). (iii) NMDA (N-methyl-Daspartate) receptor antagonists, e.g. memantine, have been suggested for GRIN2A- or GRIN2B-related diseases (Pierson et al., 2014).

(b) Nanotherapies function at an atomic, molecular or macromolecular level (McTague et al., 2015). An example would be the proposed development of a protein-protein interaction inhibitor that disrupts the helical interaction between syntaxin-1A molecules, thus mimicking the action of STXBP1 (Hussain et al., 2014).

(c) Stem cell technology will provide a platform to trial novel compounds in neurons derived from fibroblasts of patients with specific mutations, e.g. SCN1A (McTague et al., 2015).

(d) Gene therapy with delivery or expression of a wildtype gene or modification of a transcription of a mutant gene may constitute future therapies (McTague et al., 2015). Examples may include (a) an aminoglycosideinduced readthrough of a premature truncation codon of GABRG2 to rescue the cellular phenotype (Huang et al., 2012). The effect, following the introduction of a gene, would however be permanent, which may interfere with normal temporal expression patterns and have side effects. This might be mitigated by the use of optogenetics - lightsensitive proteins which can be used to activate channels and lasers to induce excitation or inhibition (McTague et al., 2015). Another approach would be allele-specific RNA in- terference - to specifically target mutated rather than wildtype alleles, e.g. in KCNQ2 encephalopathy (Matsa et al., 2014).

Novel Diagnostics It must be kept in mind that each gene may show phenotypic pleiotropy and that each epilepsy syndrome may show genetic heterogeneity (McTague et al., 2015). The phenotypic heterogeneity may arise from the type and timing of the mutations during development, the timing and location of the gene expression, epigenetic factors as well as modifier genes. In the future, there will be an expansion of non-invasive evaluation of structural focal epilepsies for seizure surgery using a combination of technologies, e.g. cEEG, MEG, PET, etc. Genetic technologies such as WES will amplify the genetic heterogeneity for the given mutation. Currently there are $>22,000$ variants now identified which will be incorporated into expanded epilepsy gene panels. One gene may be associated with phenotypic pleiotropy and there will be a need for functional validation of mutation pathogenicity. Techniques such as single cell sequencing will provide insight into somatic mosaicism. WGS has 5 million estimated variants, allowing for the identification of novel mutations or novel genes in a large group of unsolved epilepsies covering the remaining 99\% of the genome and including intronic splice sites, regulatory regions, etc. (McTague et al., 2015). Modeling of epilepsy, using patient-derived stem cells or animal models, will facilitate the study of epigenetics, gene-interactions, and environmental factors.

\section{Neuroprotection in Hypoxic Ischemic Encephalopathy}

New Therapies Hypoxic-ischemic encephalopathy in term infants occurs at a rate of about three per 1000 live-born infants in resource-rich countries and at higher rates in resource-limited countries (Kurinczuk et al., 2010; Ellis et al., 2000). Asphyxia can lead to hypoxic-ischemic encephalopathy and cerebral palsy. Cerebral palsy is one of the most costly neurologic disabilities because of its frequency (2/1000 births) and persistence over the life span (Johnston and Hoon, 2006). Knowledge of the nature, prognosis, and ways to treat brain lesions in neonatal infants has increased remarkably over the past decade. Neonatal hypoxicischaemic encephalopathy (HIE) in term infants involves a progressive cascade of excito-oxidative events that unfold in the brain after an asphyxial insult. In the laboratory, this cascade can be blocked to protect brain tissue through the process of neuroprotection. The interval between the initial hypoxic-ischemic insult and delayed energy failure includes the latent period after resuscitation when the infant appears more active for 8-24 hours but then develops seizures and signs of encephalopathy (Tan et al., 1996; Thoresen et al., 2000). The experimental evidence suggests that activation of excitatory glutamate receptors, especially NMDA receptors, occurs very early during the initial HIE insult and then oxidative stress associated with worsen- 
ing mitochondrial dysfunction and mitochondrial failure become important factors, which determine whether neurons and glia survive or die by apoptosis or necrosis (Ferriero, 2004; Johnston, 2005; Johnston et al., 2001). Inflammation plays an important role in the excito-oxidative cascade of injury (Hagberg et al., 2009), in which lipopolysaccharide has been shown to sensitise the perinatal brain to HIE and worsen injury (Wang et al., 2009), which can be reduced by administration of the antioxidant $\mathrm{N}$-acetylcysteine (Wang et al., 2007). Proof of a clinical effect was lacking until three landmark positive RCTs of moderate hypothermia for term infants with HIE were published from 2005 to 2009 (Gluckman et al., 2005; Shankaran et al., 2005; Azzopardi et al., 2009). These results have greatly improved treatment prospects for babies with asphyxia and showed that moderate hypothermia within six hours of asphyxia improves survival, without cerebral palsy or another disability, by about $40 \%$ and reduces death or neurological disability by nearly $30 \%$ (Johnston et al., 2011). The search is currently underway to discover adjuvant treatments that can further enhance the effects of hypothermia. Sex differences should also be taken into consideration when designing and testing new therapies, as preclinical testing has shown that treatments may be protective in one sex but ineffective in another (Johnston et al., 2011).

Extreme prematurity is a major risk factor for perinatal and neonatal brain injury, and can lead to white matter injury that is a precursor for a number of neurological diseases, including cerebral palsy (CP) and autism. Because neuroinflammation, mediated by activated microglia and astrocytes, is implicated in the pathogenesis of neonatal brain injury, targeted drug delivery to attenuate neuroinflammation may greatly improve therapeutic outcomes in models of perinatal white matter injury. Kannan et al., (2012) have demonstrated that systemically administered dendrimer-based N-acetyl-L-cysteine therapy in the postnatal period for a prenatal insult in a newborn rabbit model of brain injury, suppressed neuroinflammation and led to a dramatic improvement in motor function, suggesting a new window of opportunity for treatment in $\mathrm{CP}$ after birth in humans.

Dendrimers are man-made, nanoscale compounds with unique properties that make them useful to the health and pharmaceutical industry as both enhancements to existing products and as entirely new products. Dendrimers are constructed by the successive addition of layers of branching groups and each new layer is called a generation. The final generation incorporates the surface molecules that give the dendrimer the desired function for pharmaceutical, life science, chemical, electronic and materials applications.

Nance et al., (2015) have used a mouse model of ischemia-induced neonatal white matter injury to study the biodistribution of generation 4, hydroxyl-functionalised polyamidoamine dendrimers. Following systemic administration of the Cy5-labeled dendrimer (D-Cy5), they demonstrated dendrimer uptake in cells involved in ischemic injury, and in ongoing inflammation, leading to secondary in- jury. The sub-acute response to injury was driven by astrocytes. Within five days of injury, microglial proliferation and migration occured, along with limited differentiation of oligodendrocytes and oligodendrocyte death. From one day to five days after injury, a shift in dendrimer colocalisation occurred. Initially, dendrimers predominantly co-localised with astrocytes, with a subsequent shift towards microglia. Co-localisation with oligodendrocytes reduced over the same period of time, demonstrating a regionspecific uptake based on the progression of the injury. They further showed that systemic administration of a single dose of dendrimer-N-acetyl cysteine conjugate (D-NAC) at either sub-acute or delayed time points after injury, resulted in sustained attenuation of the 'detrimental' pro-inflammatory response up to nine days after injury, while not impacting the 'favourable' anti-inflammatory response. The D-NAC therapy also led to improvement in myelination, suggesting reduced white matter injury. Demonstration of treatment efficacy at later time points in the postnatal period provides a greater understanding of how microglial activation and chronic inflammation can be targeted to treat neonatal brain injury and may also provide a longer therapeutic window.

There is also potential for cell-based therapy in perinatal brain injuries in the future using stem cells, including cord blood and mesenchymal stem cells which have a neuroprotective effect in neonatal HIE in animal studies (Phillips et al., 2013). The mechanisms of action are diverse and include anti-apoptotic effects, release of growth factors, immunomodulation and activation of endogenous stem cells.

\section{Fetal and Neonatal Neurology}

In fetal neurology, there will be increasing diagnostics in utero to diagnose fetal diseases that may benefit from early interventions. Examples of this would include early ventriculo-amniotic shunt insertions (24 to 32 wks gestation) for progressive, non-infectious, obstructive hydrocephalus (Cavalheiro et al., 2003), maternal hyperoxygenation to promote early brain development in fetuses with congenital heart disease (Poryaette et al., 2016; Co-Vu et al., 2017), and metabolic therapies for inborn errors of metabolism, such as maternal high dose serine therapy to promote normal brain growth in utero in fetuses with a defect in serine biosynthesis, who would otherwise be born with microcephaly (de Konig et al., 2004).

In neonatal neurology, there will be an increasing focus on the recognition of the daily medical care needed by neonates in terms of nutritional requirements at different stages of gestation, particularly on neurodevelopmental outcomes and nutritional strategies in very low birth weight infants (Belfort and Ehrenkranz, 2017). There will also be an increasing focus on reducing pain in neonates, given the studies demonstrating that early procedural pain (skinbreaking events) in very preterm infants may contribute to impaired brain development (Brummelte et al., 2012). 


\section{CNS Infections}

Perhaps one of the most devastating congenital neurotropic viruses in the past 100 years has been the Zika virus and its extremely deleterious effect on intrauterine fetal brain development. Historically, the Zika virus (ZIKV), which is a neurotropic flavivirus carried mainly by mosquitoes of the genus Aedes, was discovered in Uganda in 1947. Between the 1960's and the 1980's, human infections related to ZIKV in Africa and Asia were typically mild. In 2007, the first large outbreak of disease was reported from the Island of Yap (one of the federated states of Micronesia) as the virus moved from South-east Asia across the Pacific (Hills et al., 2017; Talero-Gutierrez et al., 2018). From 2013 to 2014, there was an outbreak in French Polynesia with cases of Guillain-Barre syndrome (GBS), related to the ZIKV. In May 2015, the first reports of local transmission in Brazil were apparent. In July 2015, cases of GBS related to ZIKV were reported in Brazil and in October 2015, cases of congenital microcephaly arising from devastating intrauterine ZIKV exposure were reported. In February 2016, the WHO declared ZIKV associated microcephaly and other neurological disorders as a Public Health Emergency of International Concern. The ZIKV has been carried worldwide by international travel. Cases were reported in Central America and the Caribbean, with some cases in North America (Chen and Hamer 2016; Kindhauser et al., 2016). The primary vector Aedes aegypti has been recorded across all continents, including North America, Madeira, the Netherlands and the northeastern Black Sea coast, signifying adaptation to colder climates. As of March 2016, all six major geographic regions confirmed local transmission including South America (Chile, Brazil, Colombia, Suriname, Venezuela, French Guyana, Bolivia, Argentina, Ecuador, Paraguay); the Caribbean (Martinique, Puerto Rico, Saint Martin, Haiti, Barbados, US Virgin Islands, Dominican Republic, Jamaica, Curacao, Trinidad and Tobago, Aruba, Bonaire, St. Vincent and the Grenadines, Sint Maarten, Cuba, Dominica); Central America (Mexico, Panama, Honduras, El Salvador, Nicaragua, Costa Rica, Guatemala); North America (USA*, Canada*, Hawaii), Europe (France*, Italy* (+ travelers in Germany, Finland, UK, Denmark)), Africa (Cape Verde), and South-East Asia (New Caledonia, Laos, Philippines, Bangladesh, Tonga, American Samoa, Fiji, Marshall Islands, Thailand (+ Japanese travelers*)). Transmission is through the bites of the Aedes species mosquitoes, blood transfusion and sexual transmission, and the ZIKV can be found in blood and urine. The clinical incubation period following the bite of a ZIKV in fected mosquito is two to seven days. The clinical manifestations of post-natally acquired ZIKV are usually mild and include a maculopapular rash at two to 14 days (median of six days), arthralgia (at one to 14 days with a median of three and a half days), and conjunctivitis, and may invariably include myalgia, headache, retroorbital pain, joint swelling, vertigo and vomiting, and are self-resolving in approximately one week (Musso and Gubler, 2016). The autoimmune complications may include GBS or transverse myelitis (Smith and Mackenzie, 2016; Mecharles et al., 2016), whereas the prenatally acquired ZIKV manifests with devastating severe congenital microcephaly, placental loss and IUGR (Rasmussen et al., 2016; Mlakar et al., 2016). In a Task Force study by the Brazil Ministry of Health, as part of the work of the Global Health Workforce Alliance, ZIKV was identified in the amniotic fluid of two women with fetal microcephaly (Millichap, 2016). In this study, 35 infants with microcephaly were born during the period from August to October 2015. All of the mothers had lived in or visited ZIKV-affected areas during pregnancy. Of these infants, $25(71 \%)$ had severe microcephaly (HC (head circumference) $>3$ SD (standard deviations) below normal) and 17 (49\%) had at least one neurological abnormality, including hypertonia/spasticity in $37 \%$ and seizures in $9 \%$. Of the 27 infants who underwent neuroimaging, all had abnormalities with brain calcifications in $74 \%$, ventricular dilatation in $44 \%$ and neuronal migration disorders in $33 \%$. Tests for other congenital infections were negative. In another study of 42 pregnant women in Rio de Janeiro who were positive for ZIKV, fetal ultrasound demonstrated abnormalities in 12 (29\%) with two fetal deaths at 36 and 38 weeks gestation, five with IUGR, with or without microcephaly, seven with ventricular calcifications or other brain lesions, and seven with abnormal amniotic fluid volumes or cerebral or umbilical artery flows (Brasil et al., 2016). Pathophysiologically, the ZIKV has been shown to target and infect human embryonic cortical neural progenitor cells (hNPCs) and to dysregulate the cell cycle and transcription which leads to cell death (Tang et al., 2016). The diagnosis of ZIKV infection can be done by RT-PCR (reverse transcription polymerase chain reaction) during the first week of illness. The viremia occurs from days 0-11 after symptom onset. Serologic testing can be done by measurement of IgM (immunoglobulin) by ELISA (enzyme-linked immunosorbent assay), however there may be false positives with cross-reacting Dengue virus (Musso and Gluber, 2016). Confirmation can be done by plaque reduction neutralisation assays. The ZIKV may be detectable in blood, saliva, urine, sperm and amniotic fluid. At present, there are still no effective vaccines against the ZIKV, although many efforts are currently underway to accelerate the development of ZIKV vaccines using various platforms, including live attenuated virus, inactivated virus, DNA and RNA, viral vectors, and in silico-predicted immunogenic viral epitopes (Makhluf and Shresta, 2018). There is promising news from phase I, randomised, doubleblind, placebo-controlled clinical trials on aggregate safety and immunogenicity results from three trials of a purified, inactivated ZIKV vaccine which appeared to be well tolerated and elicited robust neutralising antibody titres in healthy adults (Modjarrad et al., 2017). The mainstay of therapy is prevention and symptomatic treatment. Symptomatic treatment includes antipyretics for fever and analgesics for headache and myalgia, and avoidance of nonsteroidal anti-inflammatory drugs if there is thrombocytopenia. Prevention rests on the avoidance of mosquito exposure 
with DEET or picaridin repellants to minimise day-biting Aedes, drainage of mosquito-breeding sites, application of insecticides and avoidance of contact with infected body fluids. Questions that still remain to be answered include the effect of ZIKV on the postnatally infected developing brain.

\section{Headache}

The management of headache has several exciting new modalities of treatment on the horizon. Non-medicinal therapies such as cognitive behavioural therapy (CBT) are showing promise. A randomised clinical trial of 135 youths aged 10 to 17 years, diagnosed with chronic migraine and a Pediatric Migraine Disability Assessment Score > 20 points, were assigned to CBT plus amitriptyline or to headache education plus amitriptyline (Powers et al., 2013). The use of CBT plus amitriptyline resulted in greater reductions in days with headache and migraine-related disability compared with the use of headache education plus amitriptyline. These findings supported the efficacy of CBT in the treatment of chronic migraine in children and adolescents.

Encouraging results are also being found with onabotulintoxin A. In a double-blind placebo-controlled trial of onabotulinumtoxin A versus placebo for migraine prophylaxis, there was no between-group difference for headache episodes. There were however significant reductions from baseline for headache and migraine days, cumulative hours of headache on headache days and frequency of moderate/severe headache days, which in turn reduced the burden of illness in adults with disabling chronic migraine (Aurora et al., 2010). In a second double-blind randomised placebo-controlled PREEMPT (Phase III Research Evaluating Migraine Prophylaxis Therapy) clinical program study of 1,384 adults, pooled analyses demonstrated a large mean decrease from baseline in frequency of headache days, with statistically significant between-group differences favouring onabotulinumtoxin A over placebo at week 24 (-8.4 vs -6.6; $\mathrm{P}<.001)$ and at all other time points. Significant differences favouring onabotulinumtoxin A were also observed for all secondary efficacy variables at all time points, with the exception of frequency of acute headache pain medication intakes (Dodick et al., 2010). The pooled PREEMPT results demonstrated that onabotulinumtoxin A was an effective prophylactic treatment for chronic migraine and resulted in significant improvements compared with placebo in multiple headache symptom measures, significantly reducing headache-related disability and improving functioning and overall health-related quality of life. In a retrospective chart review of the efficacy of botulinum toxin type A therapy in 10 pediatric patients with chronic daily headaches, $40 \%$ reported subjective but clinically meaningful relief, consisting of a decrease in headache intensity, and two patients additionally noted a decrease in headache frequency and thus an improvement in quality of life (Ahmed et al., 2010). The mechanism of action of onabotulinumtoxin A in chronic migraine is not fully understood, but there is evidence that this involves axonal transport via sensory fibres (Gooriah and Ahmed, 2015).

Other new non-medicinal modalities include the use of transcutaneous supraorbital nerve stimulation (tSNS) by the Cefaly device. In a double-blind, randomised shamcontrolled trial of tSNS, the device was found to be effective and safe as a preventive therapy for migraine, with a therapeutic gain of $26 \%$ which was within the range of those reported for other preventative drug and nondrug antimigraine treatments (Schoenen et al., 2013). Monthly migraine attacks, monthly headache days, and monthly acute antimigraine drug intake were also significantly reduced. In a survey of 2,313 headache sufferers in the general population, tSNS was a safe and well-tolerated treatment for migraine headches that provided satisfaction to a majority of patients who tested it for 40 days with adverse events in only $4.3 \%$, which were minor and fully reversible (Magis et al., 2013). The Cefaly (Cefaly Technology sprl, Herstal, Belgium) device has obtained approval from the American Food and Drug Administration under prescription for the prevention of episodic migraine (Riederer et al., 2015). In an open-label preliminary trial of 23 consecutive headache centre patients with chronic migraine, over half of the patients had a greater than 50\% reduction in acute medication consumption (Di Fiore et al., 2017). The Cefaly is positioned on the forehead using an adhesive electrode and precise impulses are produced during a 20 minute program, which act on the trigeminal nerve in order to prevent migraine attacks.

A second non-medicinal device which has been recently approved by the FDA for patients with migraine with aura is the Cerena Transcranial Magnetic Stimulator, a single pulse TMS stimulator which can be used as an effective preventative or abortive therapy (Zhu and Marmura, 2016).

Currently there is a focus on the development of calcitonin gene-related peptide (CGRP) antagonists (human monoclonal antibodies to CGRP or its receptor, or CGRP receptor antagonists) as a preventative treatment for migraine. In the trigeminal vascular system, the cell bodies on the trigeminal ganglion are a main source of CGRP, a neurotransmitter involved in pain and vasodilation which is believed to play a role in migraine. The role of CGRP in migraine is likely mediated by modulating nocioception and sustaining neurogenic inflammation that leads to further peripheral and central pain sensitisation (Yuan et al., 2017). Multiple pharma companies are developing CGRP biologicals (humanised monoclonal antibodies) to be used in the treatment of migraine. In a phase III placebo-controlled trial of fremanezumab (humanised monoclonal antibody targeting CGRP) in 1,130 patients, there was a lower frequency of headache (Silberstein et al., 2017). Phase II and III studies have been promising with favourable safety profiles making CGRP antagonists a major potential new therapy for the management of migraine (Yuan et al., 2017). These studies have been done in adults. The applicability to children will require future pediatric clinical trials.

Within the clinical entity of idiopathic intracranial hy- 
pertension (IIH), there are now revised diagnostic criteria for elevated opening pressures on lumbar puncture (LP) which are $>250 \mathrm{~mm}$ CSF in adults and $>280 \mathrm{~mm} \mathrm{CSF}$ in children (250 mm CSF in children if not sedated and not obese) in properly performed LPs (Friedman et al., 2013). The additional required criteria for a diagnosis of IIH are papilledema, normal neurological exam except for cranial nerve abnormalities, normal brain MRI without evidence of hydrocephalus or structural lesion or abnormal meningeal enhancement, and normal CSF composition. These investigators also provided criteria for IIH without papilledema. In a two-year, single centre prospective study of CSF opening pressure in 472 children undergoing LP as part of their routine clinical care, the reference range for the 90th percentile was $28 \mathrm{~cm}$ of water and for the 10th percentile was $11.5 \mathrm{~cm}$ of water (Avery et al., 2010). Subjects placed under moderate to deep sedation during LP had a slightly higher opening pressure as compared with those not receiving any sedatives. The patient's depth of sedation, body mass index, and sedation medication could sometimes result in small increases in opening pressure, whereas age and leg position (flexed vs extended) in the lateral decubitus position did not seem to significantly impact opening pressure (Avery, 2014). In a large retrospective, multisite cohort study of pediatric idiopathic intracranial hypertension with updated diagnostic criteria and pediatric-specific assessments, three subgroups were identified; a young group that was not overweight, an early adolescent group that was either overweight or obese, and a late adolescent group that was mostly obese (Sheldon et al., 2016).

\section{Neuroimmunology}

Advances in autoimmune encephalitis research in the past 10 years have led to the identification of new syndromes and biomarkers that have transformed the diagnostic approach to these disorders. These newly identified forms of autoimmune encephalitis may be associated with antibodies against neuronal cell-surface or synaptic proteins, and can resemble infectious encephalitis and have neurological and psychiatric manifestations without fever or CSF pleocytosis (Leypoldt et al., 2015). However, existing criteria for autoimmune encephalitis are too reliant on antibody testing and response to immunotherapy, which might delay the diagnosis.

In the field of neuroimmunology, a major breakthrough moving forward is the development of the first multicentre, consensus definition of autoimmune encephalitis by a team of experts, designed for both adults and children and allowing the clinician to navigate through the differential diagnosis to make a suspected clinical diagnosis and to initiate treatment while awaiting antibody testing, in order to avoid critical delays in immunotherapy (Graus et al., 2016). This initial diagnostic approach is based upon neurological assessment and conventional tests that are accessible to most clinicians. Through logical differential diagnosis, levels of evidence for autoimmune encephalitis (possible, probable, or definite) are achieved, which can lead to prompt immunotherapy. As the repertoire of autoimmune encephalitis in children is different from that in adults, in that the younger the child the more difficult it is to recognise specific syndromes, the guidelines for pediatric autoimmune encephalitis may be more dependent on antibody identification and other ancillary tests (Graus et al., 2016). Thus there will need to be testing of this protocol for applicability to the pediatric neurology cohort.

\section{Demyelinating disorders}

Similarly in the demyelinating disorders, autoimmune demyelination will be divided into recognised autoantibody positive disorders (e.g. aquaporin 4 antibody in neuromyelitis optica spectrum disorder (NMOSD) and MOG antibody in acute disseminated encephalomyelitis (ADEM) and NMOSD) versus disorders that are autoantibody negative (e.g. monophasic demyelination and relapsing chronic demyelination or multiple sclerosis (MS)). Novel diagnostics will expand through immunophenotyping to distinguish between different neuroinflammatory demyelinations. In the autoantibody associated demyelinations, the data is currently limited to retrospective and observational cohort studies. The natural history and treatment of subgroups should be better defined in the next two to five years and this will be facilitated through the IPMSSG (International Pediatric MS Study Group). MS in childhood manifests most frequently as a relapsing-remitting MS phenotype (RRMS) (Brenton and Banwell, 2016). As in all neurological subspecialties, multicentre collaborative RCTs (randomised controlled trials) should be the goal in order to evaluate the true efficacy and safety of different treatment strategies, given the rarity of pediatric MS. Novel therapies will rest on immunophenotyping to determine the optimal therapies for individual patients within diagnostic categories. There will be increasing RCTs for new immunomodulatory agents in pediatric MS. Data on the efficacy of the first oral agent for pediatric MS, fingolimod, should become available in the next few years through a prospective, double-blind, randomised, active-controlled study that has begun to evaluate the efficacy and safety of fingolimod versus IFN-ß1a in pediatric patients with MS (PARADIGMS), with a primary endpoint of annualised relapse rate reduction (Brenton and Banwell, 2016). Fingolimod is the first oral drug to receive FDA approval in North America and Europe for adults with relapsing-remitting MS and is a sphingosine-1-phosphate receptor modulator that prevents T-cell egress from peripheral lymphoid tissue into the peripheral and central circulation (Pelletier and Hafler, 2012). There will also be a focus on the development of neuroprotective strategies to improve remyelination. 


\section{Stroke}

Arterial ischemic stroke in newborns, young children and adults may appear the same on neuroimaging, but the outcome in terms of neurologic morbidity and mortality is markedly different due to the tremendous capacity for plasticity in the developing child's brain. Neocortical development is characterised by an extended period of synaptic proliferation that peaks in mid-childhood, with subsequent pruning through early adulthood, as well as relatively delayed maturation of neuronal arborisation in the prefrontal cortex compared with sensorimotor areas (Bianchi et al., 2013). In studies of human cortical development by anatomic brain MRI scans, between ages four to 21 years, the higher-order association cortices were shown to mature only after lower-order somatosensory and visual cortices, the functions of which they integrate were developed, and the phylogenetically older brain areas matured earlier than the newer ones (Gogtay et al., 2004). The sequence in which the cortex matured involved an early maturation of the more basic functions: motor and sensory brain areas matured first, followed by areas involved in spatial orientation, speech and language development, and attention (upper and lower parietal lobes). Later to mature were areas involved in executive function, attention and motor coordination (frontal lobes). The frontal pole, involved in taste and smell processing and the occipital pole containing the primary visual cortex, also matured early. This sequence of cortical maturation agreed with regionally relevant milestones in cognitive and functional development. There was a progressive loss of grey matter volume with maturation, the exact process of which is unknown, but may be partially explained by synaptic pruning (Huttenlocher, 1979) in combination with trophic glial and vascular changes and/or cell shrinkage (Morrison and Hof, 1997).

There are novel technologies being developed and tested to modulate plasticity in the developing brain with the aim of enhancing rehabilitation in children with perinatal injuries or infantile strokes. One of these is the use of transcranial direct-current stimulation (tDCS), which has been shown to enhance motor-learning in healthy school-aged children and which was well-tolerated and safe with no adverse events (Ciechanski and Kirton, 2017). Another modality with promise is that of combined repetitive transcranial magnetic stimulation (rTMS) and constraint-induced movement therapy (CIMT) which has been shown to enhance therapy-induced functional motor gains persisting to six months in children with stroke-induced hemiparetic cerebral palsy (Class II evidence in the PLASTIC CHAMPS Trial) (Kirton et al., 2016).

In the analysis of risk factors in pediatric arterial ischemic stroke (AIS), the Vascular Effects of Infection In Pediatric Stroke (VIPS) study tested the hypothesis that infection transiently increases the risk of AIS in children, regardless of stroke subtype (arteriopathic, cardioembolic and idiopathic). This was an international case-control study that prospectively enrolled 355 centrally confirmed cases of AIS
(29 days to 18 years of age) and 354 stroke-free controls. Infection in the week prior to stroke was reported in $18 \%$ of cases versus $3 \%$ of controls, conferring a 6.3 -fold increase risk of AIS $(\mathrm{p}<0.0001)$, with upper respiratory infections being the most common, followed by gastroenteritis, followed by otitis media (Fullerton et al., 2015). Of note, children with some/few/no routine vaccinations were at higher stroke risk than those receiving all or most, suggesting that routine vaccinations appeared to be protective. These studies have been greatly facilitated by the International Pediatric Stroke Study Group which runs multicentre ( $>55$ active IPSS centres in 2016), multinational consecutive cohort studies with the objective to develop multicentre clinical trials.

In the future, there may be a role for thrombectomy in pediatric stroke in highly selected cases, in centres with a full complement of pediatric anesthesia and a fully equipped pediatric stroke team with interventional neuroradiology and a set of well-developed institutional guidelines. Initial case selection would likely involve teenagers and adhere to the criteria for benefit from RCTs in which diagnosis is made well within six hours of stroke onset, the preceding IV tPA has been unsuccessful, there is occlusion of the proximal Circle of Willis, and the infarct core is small. To date there have been only a few reported cases of pediatric thrombectomy in AIS and the safety and efficacy of thrombectomy in children is currently unknown (Buompadre et al., 2017). Moving forward, there will need to be a registry of complications and outcomes of treated cases to determine efficacy.

\section{Movement Disorders}

In the field of movement disorders, as in other subspecialties, it is becoming clear that the genotype is not necessarily the final answer in defining the clinical phenotype which may be modified by other genes and epigenetic factors and will therefore require further analysis. A clear example of mutations in a single gene that may lead to multiple phenotypes are mutations in ATP1A3, which may present with rapid-onset dystonia-parkinsonism, alternating hemiplegia of childhood, or ataxia with dystonia (Boelman et al., 2014; Termsarasab et al., 2015; Panagiotakaki et al., 2015; Sweadner et al., 2016). Other examples include mutations in PRRT2 which may present with diverse clinical phenotypes such as paroxysmal kinesigenic dyskinesia or benign familial infantile convulsions (Chen et al., 2011; Wang et al., 2011; Meneret et al., 2012; Schubert et al., 2012). Similarly, mutations in TUBB4A may present with autosomal dominant torsion dystonia/whispering dysphonia (DYT4) (Lohmann et al., 2013) or hypomyelinating leukoencephalopathy with atrophy of the basal ganglia and cerebellum (HABC) (Simons et al., 2013). New therapeutic approaches These will focus on improved medication options based upon a better understanding of the neurobiology of the specific movement disorder, e.g. therapies may be directed, as ap- 
propriate, toward subtype specific anti-muscarinic medications, vesicular dopamine uptake inhibitors or may use gene modification approaches, such as anti-sense oligonucleotide therapy. There may also be advances in neuromodulation therapies, such as more specific deep brain stimulation targets, patient-specific stimulation paradigms, or non-invasive methods for neuromodulation.

\section{Neurotransmitter disorders}

New diseases In the field of neurotransmitter disorders, emerging new diseases are being recognised, including disorders of serotonin deficiency as well as novel monoamine neurotransmitter disorders that involve defects in dopamine transport and monoamine vesicle packaging $(\mathrm{Ng}$ et al., 2015). There will also be increasing recognition of secondary neurotransmitter disorders where the CSF profile does not fit a known primary neurotransmitter defect. Most of the secondary neurotransmitter disorders have been separated into those associated with abnormal levels of HVA or with abnormal levels of 5-HIAA (selective serotonin deficiency) ( $\mathrm{Ng}$ et al., 2015). In these conditions, disruption of monoamine metabolism may be secondary to dopaminergic and serotonergic tract degeneration or defective monoamine metabolism. Disorders with low HVA and normal 5-HIAA include mitochondrial disorders, Rett syndrome, CACNA1A mutations with ataxia, NKH, etc.; disorders with low HVA and low 5-HIAA include ADEM, GBS, urea cycle disorders, mitochondrial disorders, encephalitis, etc.; disorders with low HVA and low methyltetrahydrofolate include leukodystrophy, hypomyelination, demyelination, etc.; disorders with high HVA and normal 5-HIAA include Angleman syndrome, HIE, stroke, urea cycle disorders, etc.; disorders with low 5-HIAA only include autism, idiopathic adult-onset dystonia, etc. and those with high neopterin include EIEE, HIV infections, CNS infections, etc. ( $\mathrm{Ng}$ et al., 2015). The importance of the recognition of these patterns lies in the potential for treatment intervention, even in cases of secondary deficiencies. Enhanced understanding of novel disease mechanisms will be aided by current technologies, such as induced pluripotent stem cells (iPSC) which may be used to understand pathophysiology of disease in the appropriate neuronal subtypes and may form the basis for development of therapies (Reinhardt et al., 2013). Another powerful new technology is the development of CRISPR/Cas9 models in animals and cell lines, leading to further understanding of pathophysiologic disease mechanisms. Novel diagnostics may in clude metabolomics approaches through the use of mass spectrometry profiles, to develop biomarkers, both for diagnosis and for monitoring of treatment efficacy. Novel therapies may include gene therapy approaches as in the aromatic amino acid decarboxylase (AADC) gene therapy trial, using delivery of the AAV2-hAADC by a stereotactically inserted canula into the midbrain into the site of origin of the three major dopaminergic pathways (meso- cortical, mesolimbic and nigrostriatal) (San Sebastian et al., 2014). (See www.aadcresearch.org/page/aadc-genetherapy-trials-usa-uk/).

\section{Neuromuscular Disorders}

In the field of neuromuscular disorders, the Treat-NMD Alliance (www.treat-nmd.eu) has provided an important infrastructure and highly informative website for clinicians, researchers, families and patients, to ensure that the most promising new therapies reach patients as quickly as possible, and to provide state-of-the-art standards of care for common neuromuscular disorders, such as muscular dystrophies and spinal muscular atrophy (SMA).

Novel diagnostics

In neuromuscular disorders, novel diagnostics will increasingly use qualitative and quantitative muscle and nerve ultrasound techniques (Connolly et al., 2015; Jongloed et al., 2016). There will also be an increasing trend toward the identification of robust biomarkers for different disorders, in order to evaluate the efficacy of therapies in randomised clinical trials.

Identification of pathophysiologic mechanisms will be aided by CRISPR/Cas9 gene editing which has been useful for DMD mouse models. Gene-edited Zebra fish have also become a very valuable model for understanding the impact of mutations in congenital myopathies and muscular dystrophies (Raeker et al., 2014). The Treat-NMD network has also provided standard operating procedures (SOPs) to unify experimental protocols used to test new therapies in animal models and cells, allowing direct comparisons between studies.

\section{Novel therapies}

Internationally, novel therapies are now listed on www.clinicaltrials.gov to allow clinicians and patients to assess eligibility of patients for new or ongoing clinical trials. The major breakthrough in the treatment of SMA is the intrathecal anti-sense oligonucleotide therapy (Nusinersen) that modulates pre-messenger RNA splicing of the survival of motor neuron 2 (SMN2) gene. This has shown great promise in clinical trials of children with type 1 SMA and later-onset SMA and has generated a number of immediate and substantial medical, ethical and financial implications (Chiriboga, 2017; Messina et al., 2017; Paton, 2017; Groen et al., 2018; Mercuri et al., 2018).

Treatments for Duchenne muscular dystrophy (DMD), the most common of the muscular dystrophies, which leads to a shortened life span and considerable disability, are utilising new gene therapies such as exon skipping (exon 44, 45,51 , and 53) and stop mutation readthrough strategies. Other strategies include the use of monoclonal antibody to connective tissue growth factor (CTGF) (Morales et al., 2013). In terms of organ complications, carvedilol has been found to be protective for cardiac function (Matsumura et al., 2010). Targets for experimental treatments for DMD include strategies for cell membrane repair, gene repair (as in- 
dicated above and including morpholino oligonucleotides to block translation or gene splicing) and gene transfer, muscle or stem cell therapy, myostatin inhibition and utrophin upregulation (Guiraud and Davies, 2017; Mishra et al., 2017). Among the novel approaches to corticosteroid treatment in DMD, these have focused on the development of dissociative steroids such as VBP15 which retain membrane and anti-inflammatory subactivities associated with clinical efficacy, but do not retain the glucocorticoid response elementmediated transcriptional activities with the associated adverse side effects of gluconeogenesis, muscle catabolism and adrenal suppression (Hoffman et al., 2012; Heier et al., 2013). VBP15 has been shown to improve muscle strength in DMD mice independent of hormonal, growth or immunosuppressive effects (Heier et al., 2013).

Novel therapies for limb girdle muscular dystrophy include gene transfer for LGMD2D (alpha-sarcoglycan deficiency), using scAAVrh74 by intramuscular transfer, resulting in long-term, sustainable gene expression of alphasarcoglycan (Mendell et al., 2010). In the dysferlinopathies, novel therapy may include intramuscular gene transfer of the dysferlin gene by AAV5 (Grose et al., 2012).

\section{Neurometabolic Disorders}

Neurometabolic disorders, given the understanding of dysregulation of metabolic pathways, have become a model for pathophysiology-driven therapies. On the initial characterisation of a neurometabolic disorder, the most severe of the phenotypes is usually first recognised and described, followed by an expansion of the phenotypes based on milder mutations in a given gene. In addition, many disorders once considered rare are becoming increasingly recognised by improved clinical recognition, as well as through newborn screening, allowing for more accurate predictions of prevalence, and through the application of WES and WGS. New disease categories New disease categories are showing an ever increasing number of newly recognised pathway defects, including the expanding spectrum of congenital disorders of glycosylation (now $>100$ known disorders), which are multisystemic and can involve every organ system. They often include intellectual disability, epilepsy, hypotonia, muscle and nerve disease, and multiorgan involvement due to cell signaling, cell to cell interaction or cell migration abnormalities (Peanne et al., 2017). Other categories of disorders that are expanding include the congenital disorders of autophagy (Ebrahimi-Afkhari et al., 2016) and the CNS transporters. The congenital disorders of autophagy are an emerging novel class of inborn errors of neurometabolism. They affect the CNS at various stages of development and may lead to brain malformations, developmental delay, intellectual disability, epilepsy, movement disorders and neurodegeneration (Ebrahimi-Fakhari et al., 2016). Mutations in key autophagy genes map to different stages of this highly conserved pathway and may lead to impairment in the isolation membrane (or phagophore), autophagosome formation, maturation or autophagosomelysosome fusion. Examples include the EPG5-related Vici syndrome, the beta-propeller protein-associated neurodegeneration due to mutations in WDR45, SNX14-associated autosomal recessive cerebellar ataxia and intellectual disability syndrome, and three forms of hereditary spastic paraplegia, SPG11, SPG15, SPG49, caused by SPG11, ZFYVE26 and TECPR2 mutations, respectively. There are also associations between defective autophagy and other inborn errors of metabolism, such as the lysosomal storage diseases and neurodevelopmental diseases associated with the mTOR pathway. The modulation of autophagy may serve as a therapeutic target for pathway-specific drug development. The neuronal pathways of protein and cargo degradation are well outlined (Ebrahimi-Fakhari et al., 2014). Novel diagnostics Novel diagnostics will increasingly involve metabolomic profiles to distinguish between clinical and biochemical phenotypes within a given disorder, as well as response to therapies. There will also be increasing use of $1 \mathrm{H}$-MRS brain metabolite profiles, which are already useful for the non-invasive diagnosis and assessment of therapeutic responses in a number of disorders, including mitochondrial disorders, white matter diseases, Canavan's disease, and creatine deficiency syndromes, but which may become further expanded with finer resolution of MRS peaks. There may also be increasing use of 31P-MRS protocols of exercising muscle using an MR-compatible cycle ergometer and different exercise protocols to distinguish between different metabolic pathway defects (e.g. use of high energy phosphagens assessed with a short burst of maximal intense activity, glycolytic/glycogenolytic defects assessed by sustained intense exercise at $85 \%$ maximal exercise representing primarily anaerobic exercise, and of mitochondrial disorders assessed with repeated bouts of moderate intensity activity at $65 \%$ of maximal work, representing primarily aerobic exercise) (Rodan et al., 2015). In mitochondrial disorders, the delay in the rate of phosphocreatine recovery post-aerobic exercise is the most sensitive abnormality on 31P-MRS of mitochondrial function, since it is purportedly entirely achieved through oxidative phosphorylation (Mattei et al., 2004). This technique will also be useful for the evaluation of interventional therapies and their impact on exercise performance. Another diagnostic modality, namely BOLD-MRI, may become of increasing interest in the evaluation of vascular disorders (e.g. Moya moya for vascular reserve) and metabolic disorders (e.g. MELAS syndrome). In a pilot study, MELAS disease severity and mutation load were found to be inversely correlated with interictal cerebrovascular reactivity (CVR) on BOLD-MRI and directly correlated with frontal cerebral blood flow (on arterial spin labeling) which may serve as noninvasive prognostic markers to stratify risk for stroke-like episodes (Rodan et al., 2015).

\section{Novel therapies}

These will include mutation-based precision medicine approaches. There will also be a number of novel therapies including new target-based pharmacotherapeutic approaches in mitochondrial disorders, small molecule 
chaperone therapies for misfolded proteins, in utero fetal therapy for identified metabolic disorders (e.g. serine deficiency due to 3-phosphoglycerate dehydrogenase deficiency) (de Konig et al., 2004), new ergometric therapies for 'gene shifting' in mitochondrial disorders (Taivassalo et al., 1999; Tarnopolsky, 2014), novel in vitro fertilisation genetic therapies in mitochondrial genetic disorders (three-parent embryo) (Tavare, 2012; Liu and Chu, 2015), and international RCTs to determine drug efficacy in rare disorders. Mitochondrial disorders as a group are the most common inborn errors of metabolism. The new generation of highly potent antioxidants, such as EPI-743, may hold new promise in mitochondrial Leigh syndrome (Martinelli et al., 2012; Pastore et al., 2013). Resistance training of 12 weeks in patients with single, large-scale deletions of mitochondrial DNA led to increased muscle strength, myofibre damage and regeneration, increased proportion of neural cell adhesion molecule-positive satellite cells and improved muscle oxidative capacity, supporting the hypothesis of resistance exercise-induced mitochondrial gene-shifting in muscle containing satellite cells with low or absent levels of deleted DNA (Murphy et al., 2008). Alternating endurance exercise training (which increases VO2 max and respiratory chain enzyme activity, and improves quality of life) with resistance training (which increases strength and may lower mutation burden in patients with mitochondrial DNA deletions) and beginning an exercise program at a low intensity and duration, gradually increasing duration and intensity, tempered with abstaining from exercise on days with stressors, such as fever, infection, muscle pain, or fasting, should prove a useful therapeutic strategy for children with mitochondrial disorders using play-based exercises (Tarnopolsky, 2014). Exercise prescriptions should become a part of future therapy. There is also promising preliminary data on the therapeutic effects of L-arginine and L-citrulline supplementation in reducing the frequency, duration and severity of stroke-like episodes in MELAS syndrome (Koga et al., 2007; Siddiq et al., 2015; El-Hattab et al., 2016). Randomised, placebo-controlled clinical trials to assess the therapeutic efficacy of both on clinical complications of MELAS are needed.

Therapy in mitochondrial disorders has been largely palliative and inadequate. Therapeutic trials in mitochondrial disorders to date have been disappointing. In a Cochrane review of 1,335 studies of therapeutic interventions, including pharmacologic agents, dietary modification, nutritional supplements and exercise therapy, only 12 studies fulfilled the entry criteria of randomised controlled trials (including cross-over studies) (Pfeffer et al., 2012). On review of these studies, it was concluded that there was no clear evidence supporting the use of any intervention in mitochondrial disorders. However, the studies were conducted with different agents in clinically heterogeneous populations with evaluation of different primary and secondary endpoints, making comparisons difficult. The therapeutic strategies to date have included supportive measures, enhancement of res- piratory chain function with vitamins and cofactors, elimination of noxious compounds, shifting of heteroplasmy to lower the mutation load in mtDNA-related disorders and, most recently, cytoplasmic transfer in mtDNA-related diseases. In cytoplasmic transfer, the nucleus of an in vitrofertilised oocyte from a carrier is transferred to an enucleated oocyte from a normal donor, whereby the embryo will have the nDNA of the biological parents but the mtDNA of a healthy female mitochondrial donor (DiMauro et al., 2013). Currently, we stand at the threshold of novel pharmacologic approaches to restore mitochondrial function, including agents to stimulate and/or restore mitochondrial biogenesis, mitochondrial dynamics (fusion and fission), mitophagy and the mitochondrial unfolded protein response (Andreux et al., 2014). Mitochondrial biogenesis agents may include NAD+ boosters, sirtuins, PPAR and PCGC1 ligands; targets for mitochondrial fusion may include MFN1, MFN2, and OPA1; targets for mitochondrial fission may include dynamin-related protein 1 ; targets of mitophagy may include Parkin and PINK1 genes; and targets of proteinfolding homeostasis may include the mitochondrial unfolded protein response (UPR) which reduces the amount of unfolded proteins by stimulating mtHSP70 and HSP60 (Andreux et al., 2014). New and powerful phenotypic assays in cell-based models, as well as multicellular organisms, have been developed to explore different aspects of mitochondrial function that may serve to test and ascertain the efficacy of novel pharmacotherapies. Target-based approaches enable structure-activity relationship optimisation of hits from primary screens (e.g. estrogen-related receptor ligands, PPAR ligands, SIRT1 activators such as sirtuin 1, AMP-activated protein kinase). The disadvantage is that the target is a small part of the regulatory networks. Phenotypebased approaches in different model systems (yeast, immortalised cell lines, primary cells) allow identification of novel drugs that modulate a more global phenotype, without knowing the specific target, and may identify novel pathways (Andreux et al., 2014). Given the marked variability in mitochondrial phenotypes for a given genotype and the different genotypes that may share a similar clinical phenotype, as well as the unpredictable variability in individual clinical courses, compounded by the relative rarity of each etiology or subtype of mitochondrial disease even within a given genetic mutation, this underlines the critical importance of international collaborations for large-scale randomised double-blind placebo-controlled clinical trials. In developing children, evaluation is further complicated as improvements may be a function of their normal developmental profile rather than the therapeutic strategy, in which case repeat crossover trials, allowing for the comparison of the individual child both 'on' and 'off' the intervention at several timepoints, may help to clarify treatment efficacy. In mitochondrial disorders there will be an increasing focus on international prospective randomised, double-blind, placebo-controlled trials of well-characterised clinically homogeneous phenotypic populations using international registries and clinical consortia (e.g. North American Mi- 
tochondrial Disease Consortium (NAMDC)) with common protocols and measurement of clinically relevant primary endpoints. In 2005, the National Institute of Neurological Disorders and Stroke (NINDS) initiated the development of Common Data Elements (CDEs) to assist NINDS-funded investigators in collecting neuroscientific clinical trial research data in a standardised and consistent fashion (Grinnon et al., 2012). In 2016, an international group of mitochondrial clinicians and scientists assembled a series of tests into a toolkit for use in future mitochondrial clinical trials. There will be increasing use of a comprehensive set of CDEs, recommendations, data definitions, CRFs (case report forms), and guidelines for use in mitochondrial clinical research as developed by the NINDS (Karaa et al., 2017) to offer useful frameworks for standardisation of mitochondrial clinical trials. Such trials will also facilitate the validation of tests in this population. The widespread use of CDEs is intended to enhance mitochondrial clinical research endeavors, including natural history studies, clinical trial design, and data sharing, and to harmonise collected data in different research studies in order to allow comparisons of results in relatively rare phenotypes. Ongoing international collaboration will facilitate regular review, updates and online publication of mitochondrial CDEs, and support improved consistency of data collection and reporting. The North American Mitochondrial Disease Consortium (NAMDC) provides a national registry of patients with mitochondrial disorders. This resource, along with other national registries, will hopefully provide adequate patient numbers with homogeneous phenotypes for study and for clinical trials in order to advance a better understanding of the specific disease pathogenesis, and to ultimately allow for the development of much needed evidence-based protocols and treatments.

\section{Neuropsychiatry}

Neurobiological studies have demonstrated that behaviours and underlying brain circuits and neural growth factors (brain-derived neurotrophic factor (BDNF)) show characteristic changes across the life-span that produce 'sensitive windows of vulnerability or heightened plasticity' to particular experiences or 'resilience to psychopathology' (Casey et al., 2015). Inhibitory neurotransmission peaks early within the amygdala (during childhood), whereas increases in the prefrontal cortex begin during adolescence and do not peak until adulthood (Hartley and Lee, 2015). The gonadal hormones and BDNF levels peak during adolescence. Myelination increases gradually from childhood to adulthood. Fearlearning, extinction, and reconsolidation exhibit qualitative maturational changes across the lifespan from childhood to adolescence to adulthood. Cued and contextual fearlearning emerge during childhood, but the memories are labile. Contextual fear expression and extinction-learning are attenuated during adolescence, whereas in adulthood, extinguished fear recovers, but can be attenuated persistently through reconsolidation (Hartley and Lee, 2015). Psychi- atric disorders peak at different stages of development, e.g. ADHD/conduct disorders peak at around 10 years of age (range of five to 14 years), anxiety disorders around 12-13 years of age (range five to 18 years), schizophrenia around 17 years of age (range 13-20 years), substance abuse around 18-20 years (range 13-25 years), and mood disorders around 25 years of age (Kessler et al., 2005; Kessler and Wang, 2008). An understanding of the developmental course of these changes may inform which treatments are best at different ages. By understanding sensitive windows of development when the brain is particularly receptive to the environment, we may be better able to understand shifts and early closures of these windows due to environmental or genetic factors, allowing us to potentially expand them behaviourally and/or pharmacologically (Casey et al., 2015). Targeting more developed or dynamic/plastic circuitry may enhance treatment efficacy. Novel interventions would be based on bridging information from humans and animal models at the genetic, molecular, circuit and behavioural levels and would allow a precision medicine approach, based on the age and genetic makeup of the individual and environmental factors (Casey et al., 2015). For example, treatments for fear-related disorders such as posttraumatic stress disorder, might be tailored as a function of age to use specific interventions at a developmental stage when they may be most effective (Hartley and Lee, 2015). The attenuation of fear-extinction associated with adolescent development may hinder responses to traditional psychotherapy, such as cognitive behavioural therapy (CBT), because CBT densensitises an individual to anxiogenic stimuli through repeated exposures (e.g. extinction-learning). This is particularly topical in our current age where children in many regions of the world are exposed to significant emotional trauma through the devastation of war, poverty, illness, and separation from parents. Attention must also be paid to the constant, often unfiltered and traumatic, and age-inappropriate information intrusion/overload from the media, cell phones, iPads, etc. and the effects of these regular interruptions on attention, focus and learning. Autism There are major advances occurring in the field of autism. Autism is now recognised as a complex multifactorial developmental disorder arising from polygenic ('autism-risk' genes) and epigenetic factors, as well as non-genetic environmental risk factors (e.g. prenatal teratogens in utero, congenital viral infections, maternal anticonvulsants, postnatal autoimmune diseases, as well as viral infections, hypoxia and CNS toxins, etc.) and their interaction. ASD (autism spectrum disorder) demonstrates high heritability and familial clustering, yet the genetic causes remain only partially understood due to extensive clinical and genomic heterogeneity. Novel diagnostics Novel diagnostics include the detection of clinically relevant genetic variants in ASD by whole-genome sequencing. In the study by Jiang et al. (2013), WGS was used to examine 32 families with ASD and deleterious variants were found in four unrecognised, nine known, and eight candidate ASD risk genes. Identification of biomarkers in infants at high risk for ASD, such as eye fix- 
ation, which is present but in decline in two- to six-monthold infants later diagnosed with ASD, provides a chance for early intervention (Jones and Klin, 2013). There is a major effort underway to identify novel mechanisms leading to ASD in order to develop better therapies in the future. Genetic studies have identified mutations in genes that interfere with typical neurodevelopment in utero through childhood. Studies employing exome and genome-wide sequencing have identified nine high-confidence ASD genes (ANK2, CHD8, CUL3, DYRK1A, GRIN2B, KATNAL2, POGZ, SCN2A, TBR1) (Buxbaum et al., 2012; Willsey et al., 2013), but others are likely to be identified.

Many genes discovered to date are involved in multiple biological processes at multiple points during development, and identical mutations in the same gene can lead to wide variability in psychiatric and neurological syndromes (Malhotra and Sebat, 2012). Investigators using coexpression networks based on these high-confidence ASD 'seed' genes, leveraging a rich expression data set, including multiple human brain regions across human development and into adulthood, have demonstrated a key point of convergence in midfetal layer 5/6 cortical projection neurons (Willsey et al., 2013). The complexes of genes identified have been involved in synaptogenesis and axon motility (Park et al., 2016). It is felt that the resultant microstructural, macrostructural and functional abnormalities that emerge during brain development lead to a pattern of dysfunctional neural networks involved in socioemotional processing. Microstructurally, there is an altered ratio of short- to longdiameter axons and disorganisation of cortical layers and, macrostructurally, MRI studies of brain volume in ASD individuals have consistently shown cortical and subcortical grey matter overgrowth in early brain development (Park et al., 2016). Pathological changes have been noted on neuroimaging and neuropathological studies in the prefrontal cortex, amygdala and Nucleus acumbens (Park et al., 2016). The amygdala, which is a major component of the limbic system and the affective loop of the cortico-striatothalamocortical circuit, has roles in cognition and ASD, the Nucleus acumbens is a key structure in the social reward response, and the prefrontal cortex has roles in higher-level cognitive control processing. It also has reciprocal connections with brain regions involved in emotional processing (amygdala), memory (hippocampus) and high-order sensory regions (within the temporal cortex) (Park et al., 2016). Functionally, resting-state fMRI (functional MRI) studies have shown widespread global underconnectivity in the socioemotional networks, and task-based fMRI have shown decreased activation of networks involved in socioemotional processing (Park et al., 2016). Future treatments may target the architecture of ASD development.

\section{Novel mechanisms for ASD}

(a) Topoisomerases are expressed throughout the developing and adult brain and are mutated in some individuals with ASD. Topoisomerases appear to be important in the expression of extremely long genes in mouse and human neurons, including nearly all genes that are longer than
200 kilobases, through transcription elongation (King et al., 2013). Many high-confidence ASD candidate genes are exceptionally long and were found to be reduced in expression after topoisomerase 1 inhibition (King et al., 2013). This would suggest that chemicals and genetic mutations that impair topoisomerases could contribute to ASD and other neurodevelopmental disorders which may inform future therapies.

b) Microbiotica: in the maternal immune activation (MIA) murine model that displays GI barrier defects, microbiota alterations and features of ASD, oral treatment of MIA offspring with the human commensal Bacteroides fragilis corrects gut permeability, alters microbial composition and ameliorates defects in communication, stereotypy and anxiety-like and sensorimotor behaviours, consistent with ASD features supporting a brain-gut-microbiome connection in a mouse model of ASD (Hsaio et al., 2013). The MIA offspring display an altered metabolomics profile and B. fragilis modulates the levels of several of these metabolites. These findings support a potential probiotic therapy for GI and for behavioural symptoms in human neurodevelopmental disorders, which may provide the basis for future therapeutic interventions.

c) Though $<5 \%$ of ASD has been found to be related to metabolic disorders (Park et al., 2016), the identification of potentially treatable etiologies is important. These would include the creatine deficiency disorders, PKU (phenylketonuria), the CNS folate transporter (FOLR1), adenylosuccinate lyase deficiency, disorders of purine metabolism and mitochondrial disorders. d) Another randomised, placebocontrolled trial of methyl B12 in children with autism demonstrated improved clinician-rated symptoms of ASD that were correlated with improvements in measures of methionine metabolism and cellular methylation capacity (Hendren et al., 2016). e) Autism spectrum disorder, ADHD, schizophrenia, major depressive disorder and bipolar disorder have been shown to share genetic risk loci on genomewide analysis, which showed SNPs at four loci in regions on 3p21 and 10q24, and SNPs within two L-type voltagegated calcium channel subunits, CACNA1C and CACNB2. Pathway analysis supported a role for calcium channel signalling genes for all five disorders (Cross-Disorder Group of the Psychiatric Genomics Consortium, 2013). These risk factor gene SNPs may serve to provide early identification of ASD, and the dysregulated pathways may suggest targeted treatment interventions.

\section{Novel therapies}

The identification of pharmacogenomics indicators of ASD subphenotypes and increased understanding of the specific underlying pathophysiologic mechanisms contributing to ASD in a given child may enable targeted future therapies (e.g. antipsychotics, antidepressants, selective serotonin reuptake inhibitors, adrenergic agonists, $ß$-adrenergic antagonists, mood stabilisers, antiepileptic drugs, etc.). In medically refractory cases with self-injurious behaviour, deep-brain stimulation of the amygdala, anterior limb of the internal capsule or globus pallidus has been used with some 
benefit (Sturm et al., 2012; Stocco et al., 2014). Vaccines

There has been enormous debate regarding the possibility of a link between childhood vaccinations and the subsequent development of autism. In recent times this has become a major public health issue with vaccine preventable diseases increasing in the community, due to the fear of a 'link' between vaccinations and autism. Taylor et al., (2014) performed a meta-analysis to summarise available evidence from case-control and cohort studies on this topic (MEDLINE, PubMed, EMBASE, Google Scholar up to April, 2014). The meta-analysis findings suggested that vaccinations were NOT associated with the development of autism or ASD. Furthermore, the components of the vaccines (thimerosal or mercury) or multiple vaccines (MMR) were not associated with the development of autism or ASD. Moving forward, it will be important to reinforce these findings within the medical community, given the alarming rise of preventable infectious diseases such as measles and the associated devastating subacute sclerosing panencephalitis (SSPE).

\section{Tuberous Sclerosis}

In tuberous sclerosis, the new diagnostics rest on understanding phenotypic heterogeneity based upon genetic, biologic and environmental factors. There are improved TSC disease models and increased understanding of the TSC signaling pathways and cellular consequences of TSC deficiency. TSC is a genetic disorder resulting from overactivation of the mTOR pathway, and pharmacologic inhibition with mTOR inhibitors such as rapamycin have emerged as exciting viable target treatment options for the disease manifestations (Jeong and Wong, 2016). mTOR inhibition with Everolimus has been shown to alleviate obstructive hydrocephalus due to subependymal giant cell astrocytomas in a series of four patients, offering a significant therapeutic option to neurosurgical resection (Moavero et al., 2017).

\section{Neurooncology}

In neurooncology, there will similarly be more refined clinical diagnosis of brain tumours based on WGS. For example, medulloblastoma can be divided into a number of tumour subtypes based upon molecular markers, which can predict response to treatment in a precision medicine or personalised medicine approach (Northcott et al., 2017).

\section{Novel therapies}

These may include convection-enhanced delivery (CED) of novel compounds, including tumour-specific monoclonal antibodies for brain tumours that would not cross the blood-brain barrier and could be delivered by stereotactic catheters placed within or around the tumour (e.g. molecularly targeted cytotoxic drugs or immunotherapy in malignant glioma (Shoji et al., 2016)). Other new agents will include anti-angiogenesis agents targeting vascular endothelial growth factor and receptor signaling (Kalpathy-Cramer et al., 2017). Another therapy for recurring tumours, or ones difficult to reach surgically, is laser interstitial thermal therapy (LITT). This is a minimally invasive cytoreductive treatment using a low voltage laser to induce hyperthermia to destroy tumour cells. The extent of the thermal damage is controlled through the use of real-time MR-thermography guidance (clinicaltrials.gov) (Lagman et al., 2017). The neurosurgeon visualises and controls the treatment procedure in real-time with intraoperative MRI and a stereotactically placed probe. The fibre optic probe heats the tissue in the direction of the tumour while cooling in other directions to protect the surrounding healthy tissue. There may also be increased use of robotics in stereotactic neurosurgery and in rehabilitation. Robot-enhanced repetitive treadmill (ROBERT) therapy is being used in children with cerebral palsy (Schroeder et al., 2014).

\section{Stem Cell Therapy}

Continuing questions are being raised regarding the possibility of stem cell therapy for neurodegenerative diseases. This becomes even more complicated in the case of the developing nervous system in terms of bypassing the bloodbrain barrier and delivery of the cells to the needed locations, proliferation of the cells, self-renewal and differentiation of the stem cells into the appropriate neuronal or glial cell subtypes, developmental regulation of the expressed cellular proteins and the formation of the appropriate pathway synaptic connections.

There have been very exciting new developments identifying a drug that upregulates endogenous neurogenesis, thereby bypassing most of the issues raised above. Investigators have shown that metformin, a widely used FDAapproved diabetes drug, promotes neurogenesis and enhances spatial memory formation (Wang et al., 2012). Specifically, they have shown that an atypical PKC-CBP (protein kinase C-transcriptional coactivator) pathway is essential for the normal genesis of neurons from neural precursors, and that metformin activates this pathway to promote rodent and human neurogenesis in culture. They have further demonstrated that metformin also enhances neurogenesis in the adult mouse brain in a CBP-dependent fashion, and in so doing enhances spatial reversal-learning in the water maze. By activating an aPKC-CBP pathway, metformin thus recruits neural stem cells and enhances neural function, thereby providing a candidate pharmacological approach for central nervous system therapy. Furthermore, metformin has been shown to promote proliferation, selfrenewal and differentiation of adult neural precursor cells (NPCs) (Fatt et al., 2015). This study has shown that metformin enhances adult NPC proliferation and self-renewal, dependent upon the p53 family member and transcription factor TAp73, while it promotes neuronal differentiation of these cells by activating the AMPK(AMP-activated protein kinase)-aPKC-CBP pathway. Metformin thus represents an optimal candidate neuroregenerative agent as it is capable 
of not only expanding the adult NPC population but also subsequently driving them toward neuronal differentiation by activating two distinct molecular pathways.These findings have now been translated to a murine model of childhood hypoxic-ischemic injury. Investigators found that metformin administration activated endogenous NPCs, expanding the size of the NPC pool and promoting NPC migration and differentiation in the injured neonatal murine brain in a hypoxia-ischemia (H/I) injury model (Dadwal et al., 2015). Importantly, metformin treatment following $\mathrm{H} / \mathrm{I}$ restored sensory-motor function and lineage tracking revealed that it also led to an increase in the absolute number of subependymal-derived NPCs relative to untreated H/I controls in areas associated with sensory-motor function (Dadwal et al., 2015). Therefore, activation of endogenous NPCs is a highly promising target for therapeutic intervention in childhood brain injury models.

\section{Conclusion}

We now stand at the threshold of a brave new world with many exciting new technologies, but we must never forget the power of clinical medicine which allows us to interpret and use these tools with precision and with clinical wisdom. In the aggregate, strong collaborations between clinicians for the meticulous clinical phenotyping, expansion of the range of phenotypic expression and the entry of patients into international RCTs, the biochemists for the biochemical phenotyping and understanding of the basic pathophysiology of the underlying dysregulations and disease mechanisms arising from the protein dysfunctions, and the development of robust biomarkers to evaluate disease severity and response to therapies, as well as the geneticists for the understanding of the impact of the exonic or intronic mutations, and the roles of other regulatory genes on the affected pathway and epigenetic factors, will lead the field forward in terms of increased insight into disease pathophysiology for the development of targeted precision medicine treatment strategies and effective preventative measures. Enhanced diagnostics will be possible through metabolomic profiles, immunophenotyping, advanced neuroimaging techniques (1H-MRS, 31P-MRS, BOLD-MRI, ultrasound), algorithmic approaches and WES and WGS. Understanding of disease pathophysiology will be enhanced through the development of in vitro and in vivo models, including genetic manipulation through CRISPR/Cas9 technology in animal and cell models. Treatments may be multifaceted, including, as appropriate, pharmacotherapy, immunotherapy, physiologic therapy (e.g. ergometric therapy, deep brain stimulation), and genomic therapy (e.g. exon skipping, stop codon readthrough therapies, viral vectors encoding genes or siRNA, etc.). Evaluation of treatment efficacy will require, particularly in rare disorders, international collaborations and patient registries for prospective, randomised, double-blind, placebo-controlled trials which will be advertised through the www.clinicaltrials.gov web- site to provide access to all. There will be a focus on evidence-based guidelines for best standards of care as well as precision medicine approaches based on specific individual mutations and profiles. These collaborations in the aggregate will reduce the global burden of neurologic diseases, increasing cognitive potential and providing a brighter and healthier future for our children.

\section{Abbreviations}

RCT Randomized controlled trial

POLG Polymerase Gamma

VUS variants of unknown significance

POLG Polymerase Gamma

POLG Polymerase Gamma

\section{Acknowledgments}

The author would specifically like to gratefully acknowledge her colleagues who contributed their perspectives and insights as follows: Brenda Banwell, Helen Cross, Russell Dale, Bernard Dan, Linda De Meirleir, Gabrielle De Veber, Michael Johnston, Manju Kurian, Kenneth Mack, Steven Miller, Berge Minassian, Jonathan Mink, Francesco Muntoni, Charles Newton, James Rutka, Ingrid Scheffer, Michael Shevell and Sylvia Stockler.

\section{Competing interests}

The author has declared that there are no competing interests.

The content of this article was delivered as a plenary talk by author at the $14^{\text {th }}$ International Child Neurology Congress (ICNC) held in Amsterdam May 1-5,2106.

This is an Open Access article distributed under the terms of the Creative Commons Attribution License which permits unrestricted use, distribution, and reproduction in any medium, provided the original work is properly credited. The Creative Commons Public Domain Dedication waiver applies to the data made available in this article, unless otherwise stated.

\section{Cite this article as:}

Tein I. Expected future developments in child neurology. JICNA [Internet]. 2019;1(1). Available from: https://jicna.org/index.php/journal/article/view/jicna2019-158

\section{References}

Aartsma-Rus A, van Ommen GJ. Antisense-mediated exon skipping: a versatile tool with therapeutic and research 
applications. RNA. 2007 Oct;13(10):1609-24.

Adzhubei IA, Schmidt S, Peshkin L, Ramensky VE, Gerasimova A, Bork P, Kondrashov AS, Sunyaev SR. A method and server for predicting damaging missense mutations. Nat Methods. 2010; 7:248-9. doi: 10.1038/nmeth0410-248.

Ahmed K, Oas KH, Mack KJ, Garza I. Experience with botulinum toxin type $\mathrm{A}$ in medically intractable pediatric chronic daily headache. Pediatr Neurol. 2010 Nov;43(5):316-9. doi:10.1016/j.pediatrneurol. 2010.06.001.

Andreux PA, Houtkooper RH, Auwerx J. Pharmacologic approaches to restore mitochondrial function. Nat Rev Drug Discov 2013; 12:465-483.

Aurora SK, Dodick DW, Turkel CC, DeGryse RE, Silberstein SD, Lipton RB, Diener HC, Brin MF; PREEMPT 1 Chronic Migraine Study Group. OnabotulinumtoxinA for treatment of chronic migraine: results from the double-blind, randomized, placebo-controlled phase of the PREEMPT 1 trial. Cephalalgia. 2010 Jul;30(7):793-803. doi: 10.1177/0333102410364676. Epub 2010 Mar 17.

Avery RA. Interpretation of lumbar puncture opening pressure measurements in children. J Neuroophthalmol. 2014 Sep;34(3):284-7. doi: 10.1097/WNO.0000000000000154. Review. Erratum in: J Neuroophthalmol. 2014 Dec;34(4):e17. PMID: 25133882.

Avery RA, Shah SS, Licht DJ, Seiden JA, Huh JW, Boswinkel J, Ruppe MD, Chew A, Mistry RD, Liu GT. Reference range for cerebrospinal fluid opening pressure in children. $\mathrm{N}$ Engl J Med. 2010 Aug 26;363(9):891-3. doi: 10.1056/NEJMc1004957. No abstract available. PMID: 20818852.

Azzopardi DV, Strohm B, Edwards AD, et al. Moderate hypothermia to treat perinatal asphyxial encephalopathy. $\mathrm{N}$ Engl J Med. 2009; 361:1349-1358. [PubMed: 19797281].

Belfort MB, Ehrenkranz RA. Neurodevelopmental outcomes and nutritional strategies in very low birth weight infants. Semin Fetal Neonatal Med. 2017 Feb;22(1):42-48. doi: 10.1016/j.siny.2016.09.001.

Bender AC, Natola H, Ndong C, Holmes GL, Scott RC, Lenck-Santini P-P. Focal Scn1a knockdown induces cognitive impairment without seizures. Neurobiol Dis 2013; 54: 297-307.

Bianchi S, Stimpson CD, Duka T, Larsen MD, Janssen WG, Collins Z, Bauernfeind AL, Schapiro SJ, Baze WB, McArthur MJ, Hopkins WD, Wildman DE, Lipovich L, Kuzawa CW, Jacobs B, Hof PR, Sherwood CC. Synaptogenesis and development of pyramidal neuron dendritic morphology in the chimpanzee neocortex resembles humans. Proc Natl
Acad Sci U S A. 2013 Jun 18;110 Suppl 2:10395-401. doi: 10.1073/pnas.1301224110. Epub 2013 Jun 10. PMID: 23754422 .

Boelman C, Lagman-Bartolome AM, MacGregor DL, McCabe J, Logan WJ, Minassian BA. Identical ATP1A3 mutation causes alternating hemiplegia of childhood and rapid-onset dystonia parkinsonism phenotypes. Pediatr Neurol. 2014 Dec;51(6):850-3. doi: 10.1016/j.pediatrneurol.2014.08.015. Epub 2014 Aug 29. PMID: 25439493.

Brasil P, Pereira JP Jr, Moreira ME, Ribeiro Nogueira RM, Damasceno L, Wakimoto M, Rabello RS, Valderramos SG, Halai UA, Salles TS, Zin AA, Horovitz D, Daltro P, Boechat M, Raja Gabaglia C, Carvalho de Sequeira P, Pilotto $\mathrm{JH}$, Medialdea-Carrera R, Cotrim da Cunha D, Abreu de Carvalho LM, Pone M, Machado Siqueira A, Calvet GA, Rodrigues Baião AE, Neves ES, Nassar de Carvalho PR, Hasue RH, Marschik PB, Einspieler C, Janzen C, Cherry JD, Bispo de Filippis AM, Nielsen-Saines K. Zika Virus Infection in Pregnant Women in Rio de Janeiro. N Engl J Med. 2016 Dec 15;375(24):2321-2334.

Brenton JN, Banwell, BL. Therapeutic Approach to the Management of Pediatric Demyelinating Disease: Multiple Sclerosis and Acute Disseminated Encephalomyelitis. Neurotherapeutics. $2016 \mathrm{Jan}$; 13(1): 84-95.

Brummelte S, Grunau RE, Chau V, Poskitt KJ, Brant R, Vinall J, Gover A, Synnes AR, Miller SP. Procedural pain and brain development in premature newborns. Ann Neurol. 2012 Mar;71(3):385-96. doi: 10.1002/ana.22267. PMID: 22374882.

Buompadre MC, Andres K, Slater LA, Mohseni-Bod H, Guerguerian AM, Branson $\mathrm{H}$, Laughlin S, Armstrong D, Moharir M, deVeber G, Humpl T, Honjo O, Keshavjee S, Ichord R, Pereira V, Dlamini N. Thrombectomy for Acute Stroke in Childhood: A Case Report, Literature Review, and Recommendations. Pediatr Neurol. 2017 Jan;66:21-27. doi: 10.1016/j.pediatrneurol.2016.09.007.

Buxbaum JD, Daly MJ, Devlin B, Lehner T, Roeder K, State MW, The Autism Sequencing Consortium. The autism sequencing consortium: large-scale, high-throughput sequencing in autism spectrum disorders. Neuron 2012; 76, 1052-1056.

Carvill GL, Regan BM, Yendle SC, et al. GRIN2A mutations cause epilepsy-aphasia spectrum disorders. Nat Genet 2013; 45: 1073-76.

Casey BJ, Glatt CE, Lee FS. Treating the Developing versus Developed Brain: Translating Preclinical Mouse and Human Studies. Neuron. 2015 Jun 17;86(6):1358-68. doi: 10.1016/j.neuron.2015.05.020. Review. PMID:26087163. 
Cavalheiro S, Moron AF, Zymberg ST, Dastoli P. Fetal hydrocephalus-prenatal treatment. Childs Nerv Syst. 2003 Aug;19(7-8):561-73.

Chakraborti S, Natarajan K, Curiel J, Janke C, Liu J. The emerging role of the tubulin code: From the tubulin molecule to neuronal function and disease. Cytoskeleton (Hoboken). 2016 Oct;73(10):521-550. doi: 10.1002/cm.21290. Epub 2016 May 9.

Chen LH, Hamer DH. Zika Virus: Rapid Spread in the Western Hemisphere. Ann Intern Med. 2016 May 3;164(9):613-5. doi: 10.7326/M16-0150. Epub 2016 Feb 2. PMID: 26832396.

Chen WJ, Lin Y, Xiong ZQ, Wei W, Ni W, Tan GH, Guo SL, He J, Chen YF, Zhang QJ, Li HF, Lin Y, Murong SX, Xu J, Wang $\mathrm{N}$, Wu ZY. Exome sequencing identifies truncating mutations in PRRT2 that cause paroxysmal kinesigenic dyskinesia. Nature Genet. 43: 1252-1255, 2011.

Chinnery PF, Zeviani M. 155th ENMC workshop: polymerase gamma and disorders of mitochondrial DNA synthesis, 21-23 September 2007, Naarden, The Netherlands. Neuromuscul Disord. 2008 Mar;18(3):259-67.

Chiriboga CA. Nusinersen for the treatment of spinal muscular atrophy. Expert Rev Neurother. 2017 Oct;17(10):955962. doi: 10.1080/14737175.2017.1364159. Epub 2017 Sep 8. PMID: 28884620.

Ciechanski P, Kirton A. Transcranial Direct-Current Stimulation Can Enhance Motor Learning in Children. Cereb Cortex. 2017 May 1;27(5):2758-2767. doi: 10.1093/cercor/bhw114.

Connolly B, MacBean V, Crowley C, Lunt A, Moxham J, Rafferty GF, Hart N. Ultrasound for the assessment of peripheral skeletal muscle architecture in critical illness: a systematic review. Crit Care Med. 2015 Apr;43(4):897-905. doi: 10.1097/CCM.0000000000000821.

Co-Vu J, Lopez-Colon D, Vyas HV1, Weiner N, DeGroff C. Maternal hyperoxygenation: A potential therapy for congenital heart disease in the fetuses? A systematic review of the current literature. Echocardiography. 2017 Dec;34(12):1822-1833. doi: 10.1111/echo.13722.

Cross-Disorder Group of the Psychiatric Genomics Consortium. Identification of risk loci with shared effects on five major psychiatric disorders: a genome-wide analysis. Lancet. 2013 Apr 20;381(9875):1371-9. doi: 10.1016/S0140-6736(12)62129-1. Epub 2013 Feb 28. Erratum in: Lancet. 2013 Apr 20;381(9875):1360. PMID: 23453885.
Dadwal P, Mahmud N, Sinai L, Azimi A, Fatt M, Wondisford FE, Miller FD, Morshead CM. Activating Endogenous Neural Precursor Cells Using Metformin Leads to Neural Repair and Functional Recovery in a Model of Childhood Brain Injury. Stem Cell Reports. 2015 Aug 11;5(2):166-73. doi: 10.1016/j.stemcr.2015.06.011. Epub 2015 Jul 30.PMID: 26235894.

de Koning TJ, Klomp LW, van Oppen AC, Beemer FA, Dorland L, van den Berg I, Berger R. Prenatal and early postnatal treatment in 3-phosphoglycerate-dehydrogenase deficiency. Lancet. 2004 Dec 18-31;364(9452):2221-2.

Di Fiore P, Bussone G, Galli A, Didier H, Peccarisi C, D'Amico D, Frediani F. Transcutaneous supraorbital neurostimulation for the prevention of chronic migraine: a prospective, open-label preliminary trial. Neurol Sci. 2017 May;38(Suppl 1):201-206. doi: 10.1007/s10072-0172916-7.

DiMauro S, Schon EA, Carelli V, Hirano M. The clinical maze of mitochondrial neurology. Nat Rev Neurol 2013; 9:429-444.

Dodick DW1, Turkel CC, DeGryse RE, Aurora SK, Silberstein SD, Lipton RB, Diener HC, Brin MF; PREEMPT Chronic Migraine Study Group. OnabotulinumtoxinA for treatment of chronic migraine: pooled results from the double-blind, randomized, placebo-controlled phases of the PREEMPT clinical program. Headache. 2010 Jun;50(6):921-36. doi: 10.1111/j.1526-4610.2010.01678.x. Epub 2010 May 7.

Ebrahimi-Fakhari D, Saffari A, Wahlster L, Lu J, Byrne S, Hoffmann GF, Jungbluth H, Sahin M. Congenital disorders of autophagy: an emerging novel class of inborn errors of neuro-metabolism. Brain. 2016 Feb;139(Pt 2):317-37. doi: 10.1093/brain/awv371. Epub 2015 Dec 29. Review. PMID: 26715604.

Ebrahimi-Fakhari D, Wahlster L, Hoffmann GF, Kölker S. Emerging role of autophagy in pediatric neurodegenerative and neurometabolic diseases. Pediatr Res. 2014 Jan;75(12):217-26. doi: 10.1038/pr.2013.185. Epub 2013 Oct 28. Review. Erratum in: Pediatr Res. 2014 Sep;76(3):323. PMID: 24165736.

El-Hattab AW, Emrick LT, Hsu JW, Chanprasert S, Almannai M, Craigen WJ, Jahoor F, Scaglia F. Impaired nitric oxide production in children with MELAS syndrome and the effect of arginine and citrulline supplementation. Mol Genet Metab. 2016 Apr;117(4):407-12. doi: 10.1016/j.ymgme. 2016.01.010. Epub 2016 Jan 27.PMID: 26851065.

Ellis M, Manandhar DS, Manandhar N, Wyatt J, Bolam AJ, Costello AM. Stillbirths and neonatal encephalopathy in Kathmandu, Nepal: an estimate of the contribution of birth asphyxia to perinatal mortality in a low-income urban 
population. Paediatr Perinat Epidemiol. 2000; 14:39-52. [PubMed:10703033].

Fatt M, Hsu K, He L, Wondisford F, Miller FD, Kaplan DR, Wang J. Metformin Acts on Two Different Molecular Pathways to Enhance Adult Neural Precursor Proliferation/SelfRenewal and Differentiation. Stem Cell Reports. 2015 Dec 8;5(6):988-995. doi:10.1016/j.stemcr.2015.10.014. Epub 2015 Nov 19. PMID: 26677765.

Ferriero DM. Neonatal brain injury. N Engl J Med. 2004; 351:1985-1995. [PubMed: 15525724].

Friedman DI, Liu GT, Digre KB. Revised diagnostic criteria for the pseudotumor cerebri syndrome in adults and children. Neurology. 2013 Sep 24;81(13):1159-65. doi: 10.1212/WNL.0b013e3182a55f17. Epub 2013 Aug 21.PMID: 23966248.

Fullerton HJ, Hills NK, Elkind MS, Dowling MM, Wintermark M, Glaser CA, Tan M, Rivkin MJ, Titomanlio L, Barkovich AJ, deVeber GA; VIPS Investigators. Infection, vaccination, and childhood arterial ischemic stroke: Results of the VIPS study. Neurology. 2015 Oct 27;85(17):1459-66. doi: 10.1212/WNL. 0000000000002065. Epub 2015 Sep 30. PMID: 26423434.

Gogtay N, Giedd JN, Lusk L, Hayashi KM, Greenstein D, Vaituzis AC, Nugent TF 3rd, Herman DH, Clasen LS, Toga AW, Rapoport JL, Thompson PM. Dynamic mapping of human cortical development during childhood through early adulthood. Proc Natl Acad Sci U S A. 2004 May 25;101(21):8174-9. Epub 2004 May 17. PMID: 15148381.

Gooriah R, Ahmed F. OnabotulinumtoxinA for chronic migraine: a critical appraisal. Ther Clin Risk Manag. 2015 Jun 29;11:1003-13. doi: 10.2147/TCRM.S76964. eCollection 2015.

Graus F, Titulaer MJ, Balu R, Benseler S, Bien CG, Cellucci T, Cortese I, Dale RC, Gelfand JM, Geschwind M, Glaser CA, Honnorat J, Höftberger R, Iizuka T, Irani SR, Lancaster E, Leypoldt F, Prüss H, Rae-Grant A, Reindl M, Rosenfeld MR, Rostásy K, Saiz A, Venkatesan A, Vincent A, Wandinger KP, Waters P, Dalmau J. A clinical approach to diagnosis of autoimmune encephalitis. Lancet Neurol. 2016 Apr;15(4):391-404. doi: 10.1016/S1474-4422(15)004019. Epub 2016 Feb 20. Review. PMID: 26906964.

Grinnon ST, Miller K, Marler JR, et al. National Institute of Neurological Disorders and Stroke Common Data Element Project - approach and methods. Clinical trials (London, England). 2012;9:322-329.

Groen EJN, Talbot K, Gillingwater TH. Advances in therapy for spinal muscular atrophy: promises and challenges. Nat Rev Neurol. 2018 Feb 9. doi: 10.1038/nrneurol.2018.4.
[Epub ahead of print] Review. PMID: 29422644.

Grose WE, Clark KR, Griffin D, Malik V, Shontz KM, Montgomery CL, Lewis S, Brown RH Jr, Janssen PM, Mendell JR, Rodino-Klapac LR. Homologous recombination mediates functional recovery of dysferlin deficiency following AAV5 gene transfer. PLoS One. 2012;7(6):e39233. doi: 10.1371/journal.pone. 0039233. Epub 2012 Jun 15. PMID: 22720081.

Gluckman PD, Wyatt JS, Azzopardi D, et al. Selective head cooling with mild systemic hypothermia after neonatal encephalopathy: multicentre randomised trial. Lancet. 2005; 365:663-670. [PubMed: 15721471].

Guiraud S, Davies KE. Pharmacological advances for treatment in Duchenne muscular dystrophy. Curr Opin Pharmacol. 2017 Jun;34:36-48. doi: 10.1016/j.coph.2017.04.002. Epub 2017 May 6. Review. PMID: 28486179.

Hagberg H, Mallard C, Rousset CI, Xiaoyang W. Apoptotic mechanisms in the immature brain:involvement of mitochondria. J Child Neurol. 2009; 24:1141-1146. [PubMed: 19574577].

Hartley CA, Lee FS. Sensitive periods in affective development: nonlinear maturation of fear learning. Neuropsychopharmacology. 2015 Jan;40(1):50-60. doi: 10.1038/npp.2014.179. Epub 2014 Jul 18.

Hawkins PT, Stephens LR. PI3K signalling in inflammation. Biochim Biophys Acta. 2015 Jun;1851(6): 882-97. doi: 10.1016/j.bbalip.2014.12.006. Epub 2014 Dec 13.

Heier CR, Damsker JM, Yu Q, Dillingham BC, Huynh T, Van der Meulen JH, Sali A, Miller BK, Phadke A, Scheffer L, Quinn J, Tatem K, Jordan S, Dadgar S, Rodriguez OC, Albanese C, Calhoun M, Gordish-Dressman H, Jaiswal JK, Connor EM, McCall JM, Hoffman EP, Reeves EK, Nagaraju K. VBP15, a novel anti-inflammatory and membranestabilizer, improves muscular dystrophy without side effects. EMBO Mol Med. 2013 Oct;5(10):1569-85. doi: 10.1002/emmm.201302621. Epub 2013 Sep 9.PMID: 24014378.

Hendren RL, James SJ, Widjaja F, Lawton B, Rosenblatt A, Bent S. Randomized, Placebo-Controlled Trial of Methyl B12 for Children with Autism. J Child Adolesc Psychopharmacol. 2016 Nov;26(9):774-783. Epub 2016 Feb 18. PMID: 26889605.

Hills SL, Fischer M, Petersen LR. Epidemiology of Zika Virus Infection. J Infect Dis. 2017 Dec 16;216:S868-S874. doi: 10.1093/infdis/jix434. PMID: 29267914.

Hoffman EP, Reeves E, Damsker J, Nagaraju K, McCall JM, Connor EM, Bushby K. Novel approaches to corticos- 
teroid treatment in Duchenne muscular dystrophy. Phys Med Rehabil Clin N Am. 2012 Nov;23(4):821-8. doi: 10.1016/j.pmr.2012.08.003. Review. PMID: 23137739.

Howell KB, McMahon JM, Carvill GL, et al. SCN2A encephalopathy: a major cause of epilepsy of infancy with migrating focal seizures. Neurology 2015; 85: 958-66.

Hsiao EY, McBride SW, Hsien S, Sharon G, Hyde ER, McCue T, Codelli JA, Chow J, Reisman SE, Petrosino JF, Patterson $\mathrm{PH}$, Mazmanian SK. Microbiota modulate behavioral and physiological abnormalities associated with neurodevelopmental disorders. Cell. 2013 Dec 19;155(7):1451-63. doi: 10.1016/j.cell.2013.11.024. Epub 2013 Dec 5. PMID: 24315484.

Hsu F, Mao Y. The structure of phosphoinositide phosphatases: Insights into substrate specificity and catalysis. Biochim Biophys Acta. 2015 Jun;1851(6):698-710. doi: 10.1016/j.bbalip.2014.09.015. Epub 2014 Sep 28. Review. PMID: 25264170.

Huang X, Tian M, Hernandez CC, Hu N, Macdonald RL. The GABRG2 nonsense mutation, Q40X, associated with Dravet syndrome activated NMD and generated a truncated subunit that was partially rescued by aminoglycoside-induced stop codon read-through. Neurobiol Dis 2012; 48: 115-23.

Hussain S. Developing a PPI inhibitor-based therapy for STXBP1 haploinsufficiency-associated epileptic disorders. Front Mol Neurosci 2014; 7: 6.

Huttenlocher PR. Synaptic density in human frontal cortex - developmental changes and effects of aging. Brain Res. 1979 Mar 16;163(2):195-205.

Jeong A, Wong M. mTOR Inhibitors in Children: Current Indications and Future Directions in Neurology. Curr Neurol Neurosci Rep. 2016 Dec;16(12):102. Review. PMID: 27815691.

Jiang YH, Yuen RK, Jin X, Wang M, Chen N, Wu X, Ju J, Mei J, Shi Y, He M, Wang G, Liang J, Wang Z, Cao D, Carter MT, Chrysler C, Drmic IE, Howe JL, Lau L, Marshall CR, Merico D, Nalpathamkalam T, Thiruvahindrapuram B, Thompson A, Uddin M, Walker S, Luo J, Anagnostou E, Zwaigenbaum L, Ring RH, Wang J, Lajonchere C, Wang J, Shih A, Szatmari P, Yang H, Dawson G, Li Y, Scherer SW. Detection of clinically relevant genetic variants in autism spectrum disorder by whole-genome sequencing. Am J Hum Genet. 2013 Aug 8;93(2):249-63. doi: 10.1016/j.ajhg.2013.06.012. Epub 2013 Jul 11. PMID: 23849776.

Johnston MV. Excitotoxicity in perinatal brain injury. Brain Pathol. 2005; 15:234-240. [PubMed:16196390].

Johnston MV, Fatemi A, Wilson MA, Northington F.
Treatment advances in neonatal neuroprotection and neurointensive care. Lancet Neurol. 2011 Apr;10(4):372-82. doi: 10.1016/S1474-4422(11)70016-3. Review.PMID: 21435600 .

Johnston MV, Hoon AH Jr. Cerebral palsy. Neuromolecular Med 2006;8(4):435-450. [PubMed:17028368].

Johnston MV, Trescher WH, Ishida A, Nakajima W. Neurobiology of hypoxic-ischemic injury in the developing brain. Pediatric Res. 2001; 49:735-741.

Jones W, Klin A. Attention to eyes is present but in decline in 2-6-month-old infants later diagnosed with autism. Nature. 2013 Dec 19;504(7480):427-31. doi: 10.1038/nature12715. Epub 2013 Nov 6.

Jongbloed BA, Haakma W, Goedee HS, Bos JW, Bos C, Hendrikse J, Van Den Berg LH, Van Der Pol WL. Comparative study of peripheral nerve Mri and ultrasound in multifocal motor neuropathy and amyotrophic lateral sclerosis. Muscle Nerve. 2016 Dec;54(6):1133-1135. doi: 10.1002/mus.25391. Epub 2016 Oct 1. PMID: 27571543.

Kalpathy-Cramer J, Chandra V, Da X, Ou Y, Emblem KE, Muzikansky A, Cai X, Douw L, Evans JG, Dietrich J, Chi AS, Wen PY, Stufflebeam S, Rosen B, Duda DG, Jain RK, Batchelor TT, Gerstner ER. Phase II study of tivozanib, an oral VEGFR inhibitor, in patients with recurrent glioblastoma. J Neurooncol. 2017 Feb;131(3):603-610. doi: 10.1007/s11060-016-2332-5. Epub 2016 Nov 16. PMID: 27853960 .

Karaa A, Rahman S, Lombès A, Yu-Wai-Man P, Sheikh MK, Alai-Hansen S, Cohen BH, Dimmock D, Emrick L, Falk MJ, McCormack S, Mirsky D, Moore T, Parikh S, Shoffner $\mathrm{J}$, Taivassalo T, Tarnopolsky M, Tein I, Odenkirchen JC, Goldstein A; Mito Working Group Member Participants: Common data elements for clinical research in mitochondrial disease: a National Institute for Neurological Disorders and Stroke project. J Inherit Metab Dis. 2017 May;40(3):403-414. doi: 10.1007/s10545-017-0035-5. Epub 2017 Mar 16. Erratum in: J Inherit Metab Dis. 2017 Oct 4;:PMID: 28303425.

Keeling KM1, Xue X, Gunn G, Bedwell DM. Therapeutics based on stop codon readthrough. Annu Rev Genomics Hum Genet. 2014;15:371-94. doi: 10.1146/annurevgenom-091212-153527. Epub 2014 Apr 18.

Kessler RC, Berglund P, Demler O, Jin R, Merikangas $\mathrm{KR}$, Walters EE. Lifetime prevalence and age-of-onset distributions of DSM-IV disorders in the National Comorbidity Survey Replication. Arch Gen Psychiatry. 2005 Jun;62(6):593-602. Erratum in: Arch Gen Psychiatry. 2005 Jul;62(7):768. Merikangas, Kathleen R [added]. 
Kessler RC, Wang PS. The descriptive epidemiology of commonly occurring mental disorders in the United States. Annual Review of Public Health. 2008; 29-115-129.

Kindhauser MK, Allen T, Frank V, Santhana RS, Dye C. Zika: the origin and spread of a mosquito-borne virus. Bull World Health Organ. 2016 Sep 1;94(9):675-686C. Epub 2016 Feb 9.

King IF, Yandava CN, Mabb AM, Hsiao JS, Huang HS, Pearson BL, Calabrese JM, Starmer J, Parker JS, Magnuson T, Chamberlain SJ, Philpot BD, Zylka MJ. Topoisomerases facilitate transcription of long genes linked to autism. Nature. 2013 Sep 5;501(7465):58-62. doi: 10.1038/nature12504. Epub 2013 Aug 28. PMID: 23995680.

Kirton A, Andersen J, Herrero M, Nettel-Aguirre A, Carsolio L, Damji O, Keess J, Mineyko A, Hodge J, Hill MD. Brain stimulation and constraint for perinatal stroke hemiparesis: The PLASTIC CHAMPS Trial. Neurology. 2016 May 3;86(18):1659-67. doi: 10.1212/WNL.0000000000002646. PMID: 27029628.

Kitamura K, Yanazawa M, Sugiyama N, et al. Mutation of ARX causes abnormal development of forebrain and testes in mice and X-linked lissencephaly with abnormal genitalia in humans. Nat Genet 2002; 32: 359-69.

Koga Y, Akita Y, Nishioka J, Yatsuga S, Povalko N, Katayama K, Matsuishi T. MELAS and L-arginine therapy. Mitochondrion. 2007 Feb-Apr;7(1-2):133-9. Epub 2006 Dec 5. PMID: 17276739.

Kurinczuk JJ, White-Koning M, Badawi N. Epidemiology of neonatal encephalopathy and hypoxic-ischaemic encephalopathy. Early Hum Dev. 2010; 86:329-338. [PubMed: 20554402].

Lagman C, Chung LK, Pelargos PE, Ung N, Bui TT, Lee SJ, Voth BL, Yang I. Laser neurosurgery: A systematic analysis of magnetic resonance-guided laser interstitial thermal therapies. J Clin Neurosci. 2017 Feb;36:20-26. doi: 10.1016/j.jocn.2016.10.019. Epub 2016 Nov 9. Review. PMID: 27838155.

Leypoldt F, Armangue T, Dalmau J. Autoimmune encephalopathies. Ann N Y Acad Sci 2015; 1338: 94-114.

Lesca G, Rudolf G, Bruneau N, et al. GRIN2A mutations in acquired epileptic aphasia and related childhood focal epilepsies and encephalopathies with speech and language dysfunction. Nat Genet 2013; 45: 1061-66.

Liu HS, Chu PL. Three-parent embryo: The therapeutic future for inherited mitochondrial diseases. J Formos Med Assoc. 2015 Nov;114(11):1027-8. doi: 10.1016/j.jfma.2014.04.007. Epub 2014 Jun 17. No abstract available. PMID: 24951160.

Lohmann, K., Wilcox, R. A., Winkler, S., Ramirez, A., Rakovic, A., Park, J.-S., Arns, B., Lohnau, T., Groen, J., Kasten, M., Bruggemann, N., Hagenah, J., and 17 others. Whispering dysphonia (DYT4 dystonia) is caused by a mutation in the TUBB4 gene. Ann. Neurol 2013; 73: 537-545.

Magis D, Sava S, d'Elia TS, Baschi R, Schoenen J. Safety and patients' satisfaction of transcutaneous supraorbital neurostimulation (tSNS) with the Cefaly $\AA$ device in headache treatment: a survey of 2,313 headache sufferers in the general population. J Headache Pain. 2013 Dec 1;14:95. doi: 10.1186/1129-2377-14-95.

Makhluf H, Shresta S. Development of Zika Virus Vaccines. Vaccines (Basel). 2018 Jan 18;6(1). pii: E7. doi: 10.3390/vaccines6010007.

Malhotra, D., and Sebat, J. CNVs: harbingers of a rare variant revolution in psychiatric genetics. Cell 2012; 148, $1223-1241$.

Martinelli D1, Catteruccia M, Piemonte F, Pastore A, Tozzi G, Dionisi-Vici C, Pontrelli G, Corsetti T, Livadiotti S, Kheifets V, Hinman A, Shrader WD, Thoolen M, Klein MB, Bertini E, Miller G. EPI-743 reverses the progression of the pediatric mitochondrial disease-genetically defined Leigh Syndrome. Mol Genet Metab. 2012 Nov;107(3):383-8. doi: 10.1016/j.ymgme.2012.09.007. Epub 2012 Sep 10.

Matsa E, Dixon JE, Medway C, et al. Allele-specifi c RNA interference rescues the long-QT syndrome phenotype in human-induced pluripotency stem cell cardiomyocytes. Eur Heart J 2014; 35: 1078-87.

Matsumura T, Tamura T, Kuru S, Kikuchi Y, Kawai M. Carvedilol can prevent cardiac events in Duchenne muscular dystrophy. Intern Med. 2010;49(14):1357-63. Epub 2010 Jul 15. PMID: 20647648.

Mattei JP, Bendahan D, Cozzone P. P-31 magnetic resonance spectroscopy. A tool for diagnostic purposes and pathophysiological insights in muscle diseases. Reumatismo. 2004; 56:9-14.PMID:15201936.

McTague A, Howell KB, Cross JH, Kurian MA, Scheffer IE. The genetic landscape of the epileptic encephalopathies of infancy and childhood. Lancet Neurol. 2016 Mar;15(3):304-16. doi:10.1016/S1474-4422(15)00250-1. Epub 2015 Nov 17.

Mécharles S1, Herrmann C2, Poullain P3, Tran TH1, Deschamps N1, Mathon G3, Landais A1, Breurec S4, Lannuzel A5. Acute myelitis due to Zika virus infection. Lancet. 
TEIN I. JICNA 2019;1(1)

2016 Apr 2;387(10026):1481. doi: 10.1016/S01406736(16)00644-9. Epub 2016 Mar 4.

Mendell JR, Rodino-Klapac LR, Rosales XQ, Coley BD, Galloway G, Lewis S, Malik V, Shilling C, Byrne BJ, Conlon T, Campbell KJ, Bremer WG, Taylor LE, Flanigan KM, GastierFoster JM, Astbury C, Kota J, Sahenk Z, Walker CM, Clark KR. Sustained alpha-sarcoglycan gene expression after gene transfer in limb-girdle muscular dystrophy, type 2D. Ann Neurol. 2010 Nov;68(5):629-38. doi: 10.1002/ana.22251.

Meneret, A., Grabli, D., Depienne, C., Gaudebout, C., Picard, F., Durr, A., Lagroua, I., Bouteiller, D., Mignot, C., Doummar, D., Anheim, M., Tranchant, C., and 9 others, PRRT2 mutations: a major cause of paroxysmal kinesigenic dyskinesia in the European population. Neurology 79: 170-174, 2012.

Mercuri E, Darras BT, Chiriboga CA, Day JW, Campbell C, Connolly AM, Iannaccone ST, Kirschner J, Kuntz NL, Saito K, Shieh PB, Tulinius M, Mazzone ES, Montes J, Bishop KM, Yang Q, Foster R, Gheuens S, Bennett CF, Farwell W, Schneider E, De Vivo DC, Finkel RS; CHERISH Study Group. Nusinersen versus Sham Control in Later-Onset Spinal Muscular Atrophy. N Engl J Med. 2018 Feb 15;378(7):625-635. doi: 10.1056/NEJMoa1710504. PMID: 29443664.

Messina S, Pane M, Sansone V, Bruno C, Catteruccia M, Vita G, Palermo C, Albamonte E, Pedemonte M, Bertini E, Binetti L, Mercuri E; Italian EAP working Group. Expanded access program with Nusinersen in SMA type I in Italy: Strengths and pitfalls of a successful experience. Neuromuscul Disord. 2017 Dec;27(12):1084-1086. doi: 10.1016/j.nmd.2017.09.006. Epub 2017 Sep 21. No abstract available. PMID: 29132728.

Millichap JG1. Zika Virus Infection and Microcephaly. Pediatr Neurol Briefs. 2016 Jan;30(1):8. Doi:10.15844/pedneurbriefs-30-1-7.

Milligan CJ1, Li M, Gazina EV, Heron SE, Nair U, Trager C, Reid CA, Venkat A, Younkin DP, Dlugos DJ, Petrovski S, Goldstein DB, Dibbens LM, Scheffer IE, Berkovic SF, Petrou S. KCNT1 gain of function in 2 epilepsy phenotypes is reversed by quinidine. Ann Neurol. 2014 Apr;75(4):581-90. doi: 10.1002/ana.24128. Epub 2014 Apr 14.

Mishra MK, Loro E, Sengupta K, Wilton SD, Khurana TS. Functional improvement of dystrophic muscle by repression of utrophin: let-7c interaction. PLoS One. 2017 Oct 18;12(10):e0182676. doi: 10.1371/journal.pone.0182676. eCollection 2017. PMID: 29045431.

Mlakar J, Korva M, Tul N, Popović M, Poljšak-Prijatelj M, Mraz J, Kolenc M, Resman Rus K, Vesnaver Vipotnik T, Fabjan Vodušek V, Vizjak A, Pižem J, Petrovec M, Avšič Županc T. Zika Virus Associated with Microcephaly. N Engl
J Med. 2016 Mar 10;374(10):951-8. doi: 10.1056/NEJMoa1600651. Epub 2016 Feb 10. PMID: 26862926.

Moavero R, Carai A, Mastronuzzi A, Marciano S, Graziola F, Vigevano F, Curatolo P. Everolimus Alleviates Obstructive Hydrocephalus due to Subependymal Giant Cell Astrocytomas. Pediatr Neurol. 2017 Mar;68:59-63. doi: 10.1016/j.pediatrneurol.2016.11.003. Epub 2017 Jan 3. PMID: 28162859.

Modjarrad K, Lin L, George SL, Stephenson KE, Eckels KH, De La Barrera RA, Jarman RG, Sondergaard E, Tennant J, Ansel JL, Mills K, Koren M, Robb ML, Barrett J, Thompson J, Kosel AE, Dawson P, Hale A, Tan CS, Walsh SR, Meyer KE, Brien J, Crowell TA, Blazevic A, Mosby K, Larocca RA, Abbink P, Boyd M, Bricault CA, Seaman MS, Basil A, Walsh M, Tonwe V, Hoft DF, Thomas SJ, Barouch DH, Michael NL. Preliminary aggregate safety and immunogenicity results from three trials of a purified inactivated Zika virus vaccine candidate: phase 1 , randomised, doubleblind, placebo-controlled clinical trials. Lancet. $2017 \mathrm{Dec}$ 4. pii: S0140-6736(17)33106-9. doi: 10.1016/S01406736(17)33106-9. [Epub ahead of print] PMID: 29217375.

Morales MG, Gutierrez J, Cabello-Verrugio C, Cabrera D, Lipson KE, Goldschmeding R, Brandan E. Reducing CTGF/CCN2 slows down $\mathrm{mdx}$ muscle dystrophy and improves cell therapy. Hum Mol Genet. 2013 Dec 15;22(24):4938-51. doi: 10.1093/hmg/ddt352. Epub 2013 Jul 30. PMID: 23904456.

Morrison JH, Hof PR. Life and death of neurons in the aging brain. Science. 1997 Oct 17;278(5337): 412-9.

Murphy JL1, Blakely EL, Schaefer AM, He L, Wyrick P, Haller RG, Taylor RW, Turnbull DM, Taivassalo T. Resistance training in patients with single, large-scale deletions of mitochondrial DNA. Brain. 2008 Nov;131(Pt 11):283240. doi: 10.1093/brain/awn252.

Musso D, Gubler DJ. Zika Virus. Clin Microbiol Rev. 2016 Jul;29(3):487-524. doi: 10.1128/CMR.00072-15. Review. PMID: 27029595.

Nance E, Porambo M, Zhang F, Mishra MK, Buelow M, Getzenberg R, Johnston M, Kannan RM, Fatemi A, Kannan S. Systemic dendrimer-drug treatment of ischemia-induced neonatal white matter injury. J Control Release. 2015 Sep 28;214:112-20. doi: 10.1016/j.jconrel.2015.07.009.

Ng J, Papandreou A, Heales SJ, Kurian MA. Monoamine neurotransmitter disorders-clinical advances and future perspectives. Nat Rev Neurol. 2015 Oct;11(10):567-84. doi: 10.1038/nrneurol.2015.172. Epub 2015 Sep 22.

$\mathrm{Ng}$ PC, Henikoff S. Predicting deleterious amino acid substitutions. Genome Res. 2001; 11:863-74. 
Noebels J. Pathway-driven discovery of epilepsy genes. Nat Neurosci 2015; 18: 344-50.

Northcott PA, Buchhalter I, Morrissy AS, Hovestadt V, Weischenfeldt J, Ehrenberger T, Gröbner S, Segura-Wang M, Zichner T, Rudneva VA, Warnatz HJ, Sidiropoulos N, Phillips AH, Schumacher S, Kleinheinz K, Waszak SM, Erkek S, Jones DTW, Worst BC, Kool M, Zapatka M, Jäger N, Chavez L, Hutter B, Bieg M, Paramasivam N, Heinold M, Gu Z, Ishaque N, Jäger-Schmidt C, Imbusch CD, Jugold A, Hübschmann D, Risch T, Amstislavskiy V, Gonzalez FGR, Weber UD, Wolf S, Robinson GW, Zhou X, Wu G, Finkelstein D, Liu Y, Cavalli FMG, Luu B, Ramaswamy V, Wu X, Koster J, Ryzhova M, Cho YJ, Pomeroy SL, Herold-Mende C, Schuhmann M, Ebinger M, Liau LM, Mora J, McLendon RE, Jabado N, Kumabe T, Chuah E, Ma Y, Moore RA, Mungall AJ, Mungall KL, Thiessen N, Tse K, Wong T, Jones SJM, Witt O, Milde T, Von Deimling A, Capper D, Korshunov A, Yaspo ML, Kriwacki R, Gajjar A, Zhang J, Beroukhim R, Fraenkel E, Korbel JO, Brors B, Schlesner M, Eils R, Marra MA, Pfister SM, Taylor MD, Lichter P. The whole-genome landscape of medulloblastoma subtypes. Nature. $2017 \mathrm{Jul}$ 19;547(7663):311-317. doi: 10.1038/nature22973. PMID: 28726821 .

Ohtahara S. A study on the age dependent epileptic encephalopathy. No To Hattatsu 1977; 9: 2-21.

Oliver KL, Lukic V, Thorne NP, Berkovic SF, Scheff er IE, Bahlo M. Harnessing gene expression networks to prioritize candidate epileptic encephalopathy genes. PLoS One 2014; 9: e102079.

Orhan G, Bock M, Schepers D, et al. Dominant-negative effects of KCNQ2 mutations are associated with epileptic encephalopathy. Ann Neurol 2014; 75: 382-94.

Panagiotakaki E, De Grandis E, Stagnaro M, Heinzen EL, Fons C, Sisodiya S, de Vries B, Goubau C, Weckhuysen S, Kemlink D, Scheffer I, Lesca G, Rabilloud M, Klich A, Ramirez-Camacho A, Ulate-Campos A, Campistol J, Giannotta M, Moutard ML, Doummar D, Hubsch-Bonneaud C, Jaffer F, Cross H, Gurrieri F, Tiziano D, Nevsimalova S, Nicole S, Neville B, van den Maagdenberg AM, Mikati M, Goldstein DB, Vavassori R, Arzimanoglou A, The Italian IBAHC Consortium, The French AHC Consortium, The International AHC Consortium. Clinical profile of patients with ATP1A3 mutations in Alternating Hemiplegia of Childhood-a study of 155 patients. Orphanet J Rare Dis. 2015 Sep 26;10:123. doi: 10.1186/s13023-015-03355.PMID: 26410222.

Park HR, Lee JM, Moon HE, Lee DS, Kim BN, Kim J, Kim DG, Paek SH. A Short Review on the Current Understanding of Autism Spectrum Disorders. Exp Neurobiol. 2016 Feb;25(1):1-13. doi: 10.5607/en.2016.25.1.1. Epub 2016
Jan 28. Review. PMID:26924928.

Pastore A, Petrillo S, Tozzi G, Carrozzo R, Martinelli D, Dionisi-Vici C, Di Giovamberardino G, Ceravolo F, Klein MB, Miller G, Enns GM, Bertini E, Piemonte F. Glutathione: a redox signature in monitoring EPI-743 therapy in children with mitochondrial encephalomyopathies. Mol Genet Metab. 2013 Jun;109(2):208-14. doi: 10.1016/j.ymgme.2013.03.011. Epub 2013 Mar 24. PMID: 23583222.

Paton DM. Nusinersen: antisense oligonucleotide to increase SMN protein production in spinal muscular atrophy. Drugs Today (Barc). 2017 Jun;53(6):327-337. doi: 10.1358/dot.2017.53.6.2652413. Review. PMID: 28799578 .

Péanne R, de Lonlay P, Foulquier F, Kornak U, Lefeber DJ, Morava E, Pérez B, Seta N, Thiel C, Van Schaftingen E, Matthijs G, Jaeken J. Congenital disorders of glycosylation (CDG): Quo vadis? Eur J Med Genet. 2017 Oct 25. pii: S1769-7212(17)30494-9. doi: 10.1016/j.ejmg.2017.10.012. [Epub ahead of print] Review. PMID: 29079546.

Pelletier D, Hafler DA. Fingolimod for multiple sclerosis. N Engl J Med. 2012;366:339-347. doi: 10.1056/NEJMct1101691.

Pfeffer G, Majamaa K, Turnbull DM, Thorburn D, Chinnery PF. Treatment for mitochondrial disorders. Cochrane Database Syst Rev 2012; 4:CD004426. Doi: 10.1002/14651858.CD004426.pub3.

Phillips AW, Johnston MV, Fatemi A. The potential for cellbased therapy in perinatal brain injuries. Transl Stroke Res. 2013 Apr;4(2):137-48. doi: 10.1007/s12975-013-0254-5. Review. PMID: 23814628.

Pierson TM, Yuan H, Marsh ED, et al, and the PhD for the NISC Comparative Sequencing Program. GRIN2A mutation and early-onset epileptic encephalopathy: personalized therapy with memantine. Ann Clin Transl Neurol 2014; 1: 190-98.

Porayette P, Madathil S, Sun L, Jaeggi E, Grosse-Wortmann L, Yoo SJ, Hickey E, Miller SP, Macgowan CK, Seed M. MRI reveals hemodynamic changes with acute maternal hyperoxygenation in human fetuses with and without congenital heart disease. Prenat Diagn. 2016 Mar;36(3):274-81. doi: 10.1002/pd.4762.

Powers SW, Kashikar-Zuck SM, Allen JR, LeCates SL, Slater SK, Zafar M, Kabbouche MA, O'Brien HL,Shenk CE, Rausch JR, Hershey AD. Cognitive behavioral therapy plus amitriptyline for chronic migraine in children and adolescents: a randomized clinical trial. JAMA. 2013 Dec 
25;310(24):2622-30. doi: 10.1001/jama.2013.282533.

Raeker MÖ, Shavit JA, Dowling JJ, Michele DE, Russell MW. Membrane-myofibril cross-talk in myofibrillogenesis and in muscular dystrophy pathogenesis: lessons from the zebrafish. Front Physiol. 2014 Jan 28;5:14. doi: 10.3389/fphys.2014.00014. eCollection 2014. PMID: 24478725

Rasmussen SA, Jamieson DJ, Honein MA, Petersen LR. Zika Virus and Birth Defects-Reviewing the Evidence for Causality. N Engl J Med. 2016 May 19;374(20):1981-7. doi: 10.1056/NEJMsr1604338. Epub 2016 Apr 13. No abstract available. PMID: 27074377.

Reinhardt P, Schmid B, Burbulla LF, Schöndorf DC, Wagner L, Glatza M, Höing S, Hargus G, Heck SA, Dhingra A, Wu G, Müller S, Brockmann K, Kluba T, Maisel M, Krüger R, Berg D, Tsytsyura Y, Thiel CS, Psathaki OE, Klingauf J, Kuhlmann T, Klewin M, Müller H, Gasser T, Schöler HR, Sterneckert J. Genetic correction of a LRRK2 mutation in human iPSCs links parkinsonian neurodegeneration to ERK-dependent changes in gene expression. Cell Stem Cell. 2013 Mar 7;12(3):354-67. doi: 10.1016/j.stem.2013.01.008.

Riederer F, Penning S, Schoenen J. Transcutaneous Supraorbital Nerve Stimulation (t-SNS) with the Cefaly $<$ sup $>\AA</$ sup $>$ Device for Migraine Prevention: A Review of the Available Data. Pain Ther. 2015 Oct 14. [Epub ahead of print] PMID: 26467451.

Rodan LH, Poublanc J, Fisher JA, Sobczyk O, Wong T, Hlasny E, Mikulis D, Tein I. Cerebral hyperperfusion and decreased cerebrovascular reactivity correlate with neurologic disease severity in MELAS. Mitochondrion. 2015 May;22:66-74. doi: 10.1016/j.mito.2015.03.002. Epub 2015 Mar 21.PMID: 25801712.

Rodan LH, Wells GD, Banks L, Thompson S, Schneiderman JE, Tein I. L-Arginine Affects Aerobic Capacity and Muscle Metabolism in MELAS (Mitochondrial Encephalomyopathy, Lactic Acidosis and Stroke-Like Episodes) Syndrome. PLoS One. 2015 May 20;10(5):e0127066. doi: 10.1371/journal.pone.0127066. eCollection 2015.PMID: 25993630.

San Sebastian, W., Kells, A. P., Bringas, J., Samaranch, L., Hadaczek, P., Ciesielska, A. and Bankiewicz, K. S. Safety and tolerability of MRI-guided infusion of AAV2-hAADC into the mid-brain of non-human primate. Molecular Therapy - Methods Clinical Development. 2014; 3, 14049.

Schoenen J, Vandersmissen B, Jeangette S, Herroelen L, Vandenheede M, Gérard P, Magis D. Migraine prevention with a supraorbital transcutaneous stimulator: a randomized controlled trial. Neurology. 2013 Feb 19;80(8):697704. doi: 10.1212/WNL.0b013e3182825055. Epub 2013 Feb 6.
Schroeder AS, Von Kries R, Riedel C, Homburg M, Auffermann H, Blaschek A, Jahn K, Heinen F, Borggraefe I, Berweck. Patient-specific determinants of responsiveness to robot-enhanced treadmill therapy in children and adolescents with cerebral palsy. Dev Med Child Neurol. 2014 Dec;56(12):1172-1179. doi: 10.1111/dmcn.12564. Epub 2014 Aug 25. PMID: 25154424.

Schubert J, Paravidino R, Becker F, Berger A, Bebek N, Bianchi A, Brockmann K, Capovilla G, Dalla Bernardina B, Fukuyama Y, Hoffmann GF, Jurkat-Rott K, and 25 others. PRRT2 mutations are the major cause of benign familial infantile seizures. Hum. Mutat. 33: 1439-1443, 2012.

Shankaran S, Laptook AR, Ehrenkranz RA, et al. Wholebody hypothermia for neonates with hypoxic-ischemic encephalopathy. N Engl J Med. 2005; 353:1574-1584. [PubMed: 16221780].

Sheldon CA, Paley GL, Xiao R, Kesler A, Eyal O, Ko MW, Boisvert CJ, Avery RA, Salpietro V, Phillips PH, Heidary G, McCormack SE, Liu GT. Pediatric Idiopathic Intracranial Hypertension: Age, Gender, and Anthropometric Features at Diagnosis in a Large, Retrospective, Multisite Cohort. Ophthalmology. 2016 Nov;123(11):2424-2431. doi: 10.1016/j.ophtha.2016.08.004. Epub 2016 Sep 28.

Shoji T, Saito R, Chonan M, Shibahara I, Sato A, Kanamori $\mathrm{M}$, Sonoda $\mathrm{Y}$, Kondo $\mathrm{T}$, Ishii $\mathrm{N}$, Tominaga $\mathrm{T}$. Local convection-enhanced delivery of an anti-CD40 agonistic monoclonal antibody induces antitumor effects in mouse glioma models. Neuro Oncol. 2016 Aug;18(8):1120-8. doi: 10.1093/neuonc/now023. Epub 2016 Feb 24. PMID: 26917236.

Siddiq I, Widjaja E, Tein I. Clinical and radiologic reversal of stroke-like episodes in MELAS with high-dose L-arginine. Neurology. 2015 Jul 14;85(2):197-8. doi: 10.1212/WNL.0000000000001726. Epub 2015 Jun 12.

Silberstein SD, Dodick DW, Bigal ME, Yeung PP, Goadsby PJ, Blankenbiller T, Grozinski-Wolff M, Yang R, Ma Y, Aycardi E. Fremanezumab for the Preventive Treatment of Chronic Migraine. N Engl J Med. 2017 Nov 30;377(22):2113-2122. doi: 10.1056/NEJMoa1709038.

Simons C, Wolf NI, McNeil N, Caldovic L, Devaney JM, Takanohashi A, Crawford J, Ru K, Grimmond SM, Miller D, Tonduti D, Schmidt JL, and 9 others. A de novo mutation in the beta-tubulin gene TUBB4A results in the leukoencephalopathy hypomyelination with atrophy of the basal ganglia and cerebellum. Am. J. Hum Genet 2013; 92: 767-773.

Siva K1, Covello G, Denti MA. Exon-skipping antisense oligonucleotides to correct missplicing in neurogenetic 
diseases. Nucleic Acid Ther. 2014 Feb;24(1):69-86. doi: 10.1089/nat.2013.0461.

Smith DW, Mackenzie J. Zika virus and Guillain-Barré syndrome: another viral cause to add to the list. Lancet. 2016 Apr 9;387(10027):1486-8. doi: 10.1016/S01406736(16)00564-X. Epub 2016 Mar 2. No abstract available.

Southwell AL1, Skotte NH, Bennett CF, Hayden MR. Antisense oligonucleotide therapeutics for inherited neurodegenerative diseases. Trends Mol Med. 2012 Nov;18(11):634-43. doi: 10.1016/j.molmed.2012.09.001.

Stocco A, Baizabal-Carvallo JF. Deep brain stimulation for severe secondary stereotypies. Parkinsonism Relat Disord. 2014;20:1035-1036.

Sturm V, Fricke O, Buhrle CP, Lenartz D, Maarouf M, Treuer H, Mai JK, Lehmkuhl G. DBS in the basolateral amygdala improves symptoms of autism and related self-injurious behavior: a case report and hypothesis on the pathogenesis of the disorder. Front Hum Neurosci. 2012;6:341.

Sweadner KJ, Toro C, Whitlow CT, Snively BM, Cook JF, Ozelius LJ, Markello TC, Brashear A. ATP1A3 mutation in adult rapid-onset ataxia. PLoS One 2016; 11: e0151429.

Taivassalo T, Fu K, Johns T, Arnold D, Karpati G, Shoubridge EA. Gene shifting: a novel therapy for mitochondrial myopathy. Hum Mol Genet. 1999 Jun;8(6):1047-52. PMID: 10332036.

Talero-Gutiérrez C, Rivera-Molina A, Pérez-Pavajeau C, Ossa-Ospina I, Santos-García C, Rojas-Anaya MC, de-laTorre A. Zika virus epidemiology: from Uganda to world pandemic, an update. Epidemiol Infect. 2018:1-7. doi: 10.1017/S0950268818000419. PMID: 29536828.

Tan WK, Williams CE, During MJ, et al. Accumulation of cytotoxins during the development of seizures and edema after hypoxic-ischemic injury in late gestation fetal sheep. Pediatr Res. 1996; 39:791-797. [PubMed: 8726230].

Tang H, Hammack C, Ogden SC, Wen Z, Qian X, Li Y, Yao B, Shin J, Zhang F, Lee EM, Christian KM, Didier RA, Jin P, Song H, Ming GL. Zika Virus Infects Human Cortical Neural Progenitors and Attenuates Their Growth. Cell Stem Cell. 2016 May 5;18(5):587-90. doi:10.1016/j.stem.2016.02.016.

Taylor LE, Swerdfeger AL, Eslick GD. Vaccines are not associated with autism: an evidence-based meta-analysis of case-control and cohort studies. Vaccine. 2014 Jun 17;32(29):3623-9. doi: 10.1016/j.vaccine.2014.04.085. Epub 2014 May 9.PMID: 24814559.

Tarnopolsky MA1. Exercise as a therapeutic strategy for primary mitochondrial cytopathies. J Child Neurol. 2014 Sep;29(9):1225-34. doi: 10.1177/0883073814538512. Epub 2014 Jul 9.

Tavare A. Scientists are to investigate "three parent IVF" for preventing mitochondrial diseases. BMJ. 2012 Jan 20;344:e540. doi: 10.1136/bmj.e540. No abstract available. PMID: 22267657.

Tein I. Mitochondrial diseases: need for international collaborations. Dev Med Child Neurol. 2016 May;58(5):425. doi: $10.1111 / \mathrm{dmcn} .13120$. No abstract available. PMID: 27103187.

Termsarasab P, Yang AC, Frucht SJ. Intermediate Phenotypes of ATP1A3 Mutations: Phenotype-Genotype Correlations. Tremor Other Hyperkinet Mov (N Y). 2015 Sep 16;5:336. doi: 10.7916/D8MG7NS8. eCollection 2015.PMID: 26417536.

Thomas RH, Zhang LM, Carvill GL, et al, and the Euro EPINOMICS RES Consortium. CHD2 myoclonic encephalopathy is frequently associated with self-induced seizures. Neurology 2015; 84: 951-58.

Thoresen M. Cooling the newborn after asphyxia-physiological and experimental background and its clinical use. Semin Neonatol. 2000; 5:61-73. [PubMed: 10802751].

van Roon-Mom WM1, Aartsma-Rus A. Overview on applications of antisense-mediated exon skipping. Methods Mol Biol. 2012;867:79-96. doi: 10.1007/978-1-61779-767-56.

Vockley J, Rinaldo P, Bennett MJ, Matern D, Vladutiu GD. Synergistic heterozygosity: disease resulting from multiple partial defects in one or more metabolic pathways. Mol Genet Metab. 2000 Sep-Oct;71(1-2):10-8.

Wang JL, Cao L, Li XH, Hu ZM, Li JD, Zhang JG, Liang Y, San-A, Li N, Chen SQ, Guo JF, Jiang H, and 12 others. Identification of PRRT2 as the causative gene of paroxysmal kinesigenic dyskinesias. Brain 134: 3493-3501, 2011.

Wang J, Gallagher D, DeVito LM, Cancino GI, Tsui D, He L, Keller GM, Frankland PW, Kaplan DR, Miller FD. Metformin activates an atypical PKC-CBP pathway to promote neurogenesis and enhance spatial memory formation. Cell Stem Cell. 2012 Jul 6;11(1):23-35. doi: 10.1016/j.stem.2012.03.016. PMID: 22770240.

Wang X, Stridh L, Li W, et al. Lipopolysaccharide sensitizes neonatal hypoxic-ischemic brain injury in a MyD88dependent manner. J Immunol. 2009; 183:7471-7477. [PubMed: 19917690].

Wang X, Svedin P, Nie C, et al. N-acetylcysteine reduces 
lipopolysaccharide-sensitized hypoxic-ischemic brain injury. Ann Neurol. 2007; 61:263-271. [PubMed: 17253623].

Weckhuysen S, Mandelstam S, Suls A, et al. KCNQ2 encephalopathy: emerging phenotype of a neonatal epileptic encephalopathy. Ann Neurol 2012; 71: 15-25.

Willsey AJ, Sanders SJ, Li M, Dong S, Tebbenkamp AT, Muhle RA, Reilly SK, Lin L, Fertuzinhos S, Miller JA, Murtha MT, Bichsel C, Niu W, Cotney J, Ercan-Sencicek AG, Gockley J, Gupta AR, Han W, He X, Hoffman EJ, Klei L, Lei J, Liu W, Liu L, Lu C, Xu X, Zhu Y, Mane SM, Lein ES, Wei L, Noonan JP, Roeder K, Devlin B, Sestan $\mathrm{N}$, State MW. Coexpression networks implicate human midfetal deep cortical projection neurons in the pathogenesis of autism. Cell. 2013 Nov 21;155(5):997-1007. doi: 10.1016/j.cell.2013.10.020.PMID: 24267886.

Wishart DS, Feunang YD, Marcu A, Guo AC, Liang K, Vázquez-Fresno R, Sajed T, Johnson D, Li C, Karu N, Sayeeda Z, Lo E, Assempour N, Berjanskii M, Singhal S, Arndt D, Liang Y, Badran H, Grant J, Serra-Cayuela A, Liu Y, Mandal R, Neveu V, Pon A, Knox C, Wilson M, Manach C, Scalbert A. HMDB 4.0: the human metabolome database for 2018. Nucleic Acids Res. 2018 Jan 4;46(D1):D608-D617. doi: $10.1093 /$ nar/gkx1089.

Yu FH, Mantegazza M, Westenbroek RE, et al. Reduced sodium current in GABAergic interneurons in a mouse model of severe myoclonic epilepsy in infancy. Nat Neurosci 2006; 9: 1142-49.

Yuan H, Lauritsen CG, Kaiser EA, Silberstein SD. CGRP Monoclonal Antibodies for Migraine: Rationale and Progress. BioDrugs. 2017 Dec;31(6):487-501. doi: 10.1007/s40259017-0250-5. PMID: 29116598.

Zhu S, Marmura MJ. Non-Invasive Neuromodulation for Headache Disorders. Curr Neurol Neurosci Rep. 2016 Feb;16(2):11. doi: 10.1007/s11910-015-0620-7. Review. PMID: 26750126.

Zolkipli Z, Pedersen CB, Lamhonwah AM, Gregersen N, Tein I. Vulnerability to oxidative stress in vitro in pathophysiology of mitochondrial short-chain acyl-CoA dehydrogenase deficiency: response to antioxidants. PLoS One. 2011 Apr 1;6(4):e17534. doi: 10.1371/journal.pone.0017534. 